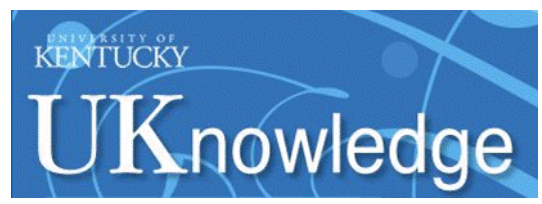

University of Kentucky

UKnowledge

\title{
Fully Coupled Internal Radiative Heat Transfer for the 3D Material Response of Heat Shield
}

\author{
Raghava S. C. Davuluri \\ University of Kentucky, raghava.sai.chaitanya@gmail.com \\ Rui Fu \\ University of Kentucky, rick.fu@uky.edu \\ Kaveh A. Tagavi \\ University of Kentucky, kaveh.tagavi@uky.edu \\ Alexandre Martin \\ University of Kentucky, alexandre.martin@uky.edu
}

Follow this and additional works at: https://uknowledge.uky.edu/me_facpub

Part of the Aerodynamics and Fluid Mechanics Commons, Heat Transfer, Combustion Commons, Materials Science and Engineering Commons, Numerical Analysis and Computation Commons, Structures and Materials Commons, Thermodynamics Commons, and the Transport Phenomena Commons

Right click to open a feedback form in a new tab to let us know how this document benefits you.

\section{Repository Citation}

Davuluri, Raghava S. C.; Fu, Rui; Tagavi, Kaveh A.; and Martin, Alexandre, "Fully Coupled Internal Radiative Heat Transfer for the 3D Material Response of Heat Shield" (2021). Mechanical Engineering Faculty Publications. 79.

https://uknowledge.uky.edu/me_facpub/79

This Conference Proceeding is brought to you for free and open access by the Mechanical Engineering at UKnowledge. It has been accepted for inclusion in Mechanical Engineering Faculty Publications by an authorized administrator of UKnowledge. For more information, please contact UKnowledge@lsv.uky.edu. 


\section{Fully Coupled Internal Radiative Heat Transfer for the 3D Material Response of Heat Shield}

Digital Object Identifier (DOI)

https://doi.org/10.2514/6.2021-3131

Notes/Citation Information

Published in AIAA AVIATION 2021 FORUM.

Copyright @ 2021 by Raghava S. C. Davuluri, Rui Fu, Kaveh A. Tagavi, Alexandre Martin.

The copyright holders have granted the permission for posting the article here. 


\title{
Fully coupled internal radiative heat transfer for 3D material response of heat shield
}

\author{
Raghava S.C. Davuluri; Rui Fu† Kaveh A. Tagavi $\ddagger$ and Alexandre Martin§, \\ University of Kentucky, Lexington, KY, 40506
}

\begin{abstract}
The radiative transfer equation (RTE) is strongly coupled to the material response code KATS. A P-1 approximation model of RTE is used to account for radiation heat transfer within the material. First, the verification of the RTE model is performed by comparing the numerical and analytical solutions. Next, the coupling scheme is validated by comparing the temperature profiles of pure conduction and conduction coupled with radiative emission. The validation study is conducted on Marschall et al. cases (radiant heating, arc-jet heating, and space shuttle entry), 3D Block, 2D IsoQ sample, and Stardust Return Capsule. The validation results agree well for all the cases within a margin of error of $10 \%$. Thus, the validation results indicate that the coupling approach can simulate the thermal response of material accurately. The coupling scheme is then used to simulate a laser heating experiment that studied the impact of spectral radiative heat transfer on ablative material. The results from the laser ablation simulations indicate the expected behavior and match well with experimental ones implying the effect of spectral radiative flux on the material response.
\end{abstract}

\section{Introduction}

Space vehicles enter the planetary atmosphere at hypersonic speeds and experience high surface heat fluxes. The high enthalpy of the flow contributes to the convective heat flux and shock layer emissions to the radiative heat flux. These vehicles are equipped with Thermal Protection System (TPS) that counter these high heat fluxes and protect the vehicle from these extreme conditions. For most vehicles of interest to NASA, ablative fibrous materials are used as TPS, which undergo mass removal mechanisms to absorb the intense heat. ${ }^{1}$

The heat transfer process for these ablative materials involves different mechanisms. For a simple nonreactive fibrous material, the energy transfer takes place in the form of heat conduction through the solid and gas, and internal radiation through the porous structure. Several studies ${ }^{2-4}$ indicated that internal radiation is significant, and in some cases, dominant, mode of heat transfer and aid in volume ablation. The thermal response of the material is computationally modeled using Material Response (MR) codes. These codes use the parameter effective thermal conductivity that accounts for both heat conduction as well as internal radiation. ${ }^{2}$

It is generally assumed that the radiative flux, incident on the surface, is either reflected or absorbed to a very minute thickness within the material. The experiments by White ${ }^{5}$ who used a solar tower to irradiate Phenolic Impregnated Carbon Ablator (PICA) samples with incident flux levels at 50, 100, $150 \mathrm{~W} / \mathrm{cm} 2$, indicated no in-depth transmission and absorption in the near-infrared wavelength regime of radiative heating. However, recently, the assumption proved to be invalid when White ${ }^{6}$ conducted laser testing on silica, glass-fiber, and carbon-felt-based materials. Two types of lasers were used $-\mathrm{CO}_{2}$ laser (wavelength $=10.6$ $\mu \mathrm{m}$ ) and Fiber laser (wavelength $=1.07 \mu \mathrm{m}$ ) - which imposed a heat flux of $115 \mathrm{~W} / \mathrm{cm}^{2}$ on the samples for 30 seconds. When the two lasers irradiated the samples of the same material, it was found that the material response was quite different. The values for the parameters like mass loss, char layer thickness,

\footnotetext{
${ }^{*}$ Graduate Student, Mechanical Engineering, AIAA Student Member

${ }^{\dagger}$ Research Scientist, Mechanical Engineering, AIAA Member

¥Professor, Mechanical Engineering

§Professor, Mechanical Engineering, Associate Fellow AIAA. alexandre.martin@uky.edu
} 
maximum bondline temperature, and time to reach maximum bondline temperature were higher for the sample irradiated by Fiber laser when compared to the $\mathrm{CO}_{2}$ laser. The results indicated that the spectral radiation penetrates through a significant depth of the material and impacts the material response. Since the shock layer radiation can be expressed in terms of narrow bands of emission, ${ }^{7}$ it is important to account for the effects of spectral radiative flux in order to define the performance of TPS accurately.

The effective thermal conductivity takes into account only total radiative heat flux and does not resolve its spectral contribution. Therefore, to compute the material response to a spectral radiative flux, the heat conduction and internal radiation should be solved separately and coupled to ensure complete heat transfer through the material.

In this work, a P-1 approximation model of the Radiation Transfer Equation (RTE) is used to compute the internal radiation. The objective of the present work is to showcase the functionality of the developed tool by performing validation for cases of multi-dimensional models and simulating the laser ablation to understand the significance of spectral radiation within a material. The present work is an extension to the work performed by Martin and Panesi. ${ }^{8}$

\section{Methodology}

\section{II.A. Numerical Models}

\section{II.A.1. KATS - MR}

The material response is simulated using the MR module of KATS (Kentucky Aerothermodynamics and Thermal-response Solver). ${ }^{9-15}$ The solver employs a finite volume method on the governing equation, which is of the form:

$$
\frac{\partial \mathbf{Q}}{\partial t}+\nabla \cdot\left(\mathcal{F}-\mathcal{F}_{\boldsymbol{d}}\right)=\mathbf{S}
$$

where $\mathbf{Q}$ is a vector of conservative variables, $\mathcal{F}$ and $\mathcal{F}_{\boldsymbol{d}}$ are convective and diffusive flux matrices, and $\mathbf{S}$ is the source term vector. The vectors of conservative variables and source terms are of the form:

$$
\mathbf{Q}=\left(\begin{array}{c}
\phi \rho_{g_{1}} \\
\vdots \\
\phi \rho_{g_{n g s}} \\
\rho_{s_{1}} \\
\vdots \\
\rho_{s_{n g s}} \\
\phi \rho_{g} u \\
\phi \rho_{g} v \\
\phi \rho_{g} w \\
\phi \rho E_{g}+E_{s}
\end{array}\right), \quad \mathbf{S}=\left(\begin{array}{c}
\dot{\omega}_{g_{1}} \\
\vdots \\
\dot{\omega}_{g_{n g s}} \\
\dot{\omega}_{s_{1}} \\
\vdots \\
\dot{\omega}_{s_{n g s}} \\
D_{x} \\
D_{y} \\
D_{z} \\
S_{D}
\end{array}\right),
$$

where $\phi$ is the porosity of the material, $\rho$ is the density, $(u, v, w)$ are the components of gas velocity, $E$ is the overall energy per unit volume. $\left(D_{x}, D_{y}, D_{z}\right)$ are terms that account for diffusive effects of porous structure in the momentum equation, $S_{D}$ is the diffusive source in the energy equation, and $\dot{\omega}$ is the mass production rate of species. Subscripts $n g s$ and $n s s$ represent the number of gas species and the number of solid species, whereas $g$ and $s$ represent the gas and solid states. The convective and diffusive flux matrices in Eq. 1 are given as: 


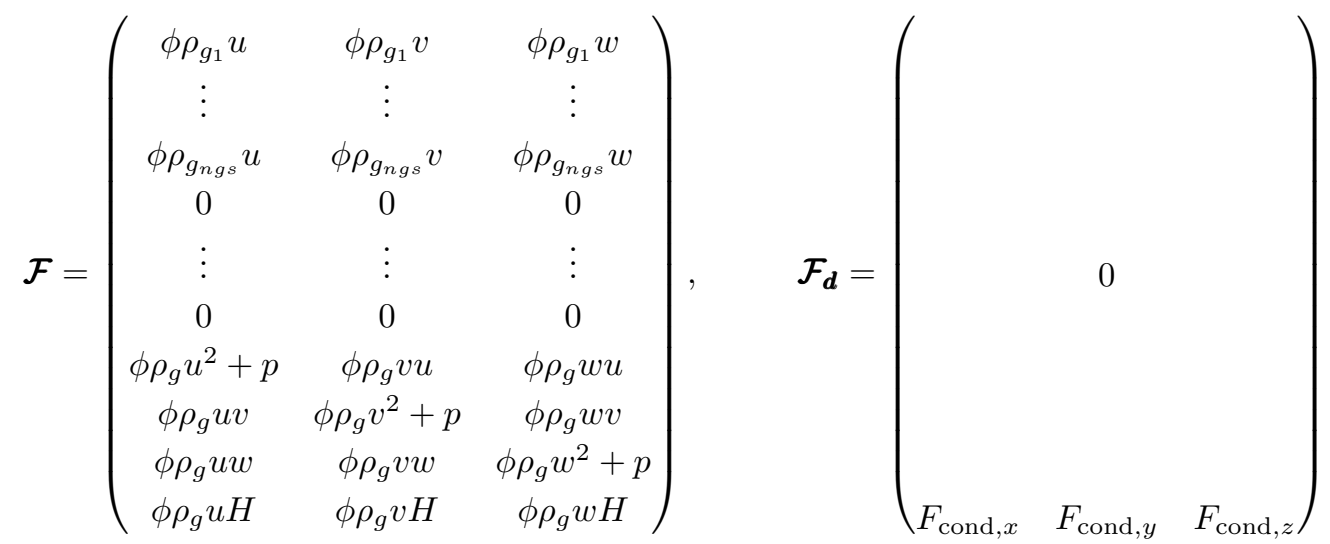

where $p$ is the static pressure, $H$ is the gas enthalpy, and $F_{\text {cond, } i}$ are the conductive heat flux components. Eq. 1 is discretized first-order in time and second-order in space. The solver uses the PETSc library ${ }^{16-18}$ to solve the linear system of equations, ParMETIS ${ }^{19}$ for domain decomposition, and MPI $^{20}$ for message passing. More information on this solver is presented in the works by Weng et al. ${ }^{9,21,22}$

\section{II.A.2. Radiation Transfer Equation}

The radiative energy balance in participating media (absorbing, emitting, and scattering media) is given by the Radiative Transfer Equation (RTE). ${ }^{23}$ RTE indicates the radiation intensity field within the enclosures as a function of location, direction, and spectral variable and is defined as:

$$
\frac{1}{c} \frac{\partial I_{\lambda}}{\partial t}+\hat{s} \cdot \nabla I_{b \lambda}=\kappa_{\lambda} I_{b \lambda}-\left(\kappa_{\lambda}+\sigma_{s \lambda}\right) I_{\lambda}+\frac{\sigma_{s \lambda}}{4 \pi} \int_{4 \pi} I_{\lambda}\left(\hat{s}_{i}\right) \phi_{s \lambda}\left(\hat{s}_{i}, \hat{s}\right) d \Omega_{i}
$$

where $\hat{s}$ is the directional unit vector, $I_{\lambda}$ is the spectral intensity, $I_{b \lambda}$ is the Planck function, $\kappa_{\lambda}$ is the spectral absorption coefficient, $\sigma_{s \lambda}$ is the spectral scattering coefficient, $\phi_{s \lambda}\left(\hat{s}_{i}, \hat{s}\right)$ is the scattering phase function, $c$ is the speed of light, and $\Omega$ is the solid angle. For most of the applications, the first term of Eq. 4 is minimal and can be neglected. ${ }^{23}$ Therefore, Eq. 4 can be re-written as

$$
\hat{s} \cdot \nabla I_{b \lambda}=\frac{d I_{\lambda}}{d s}=\kappa_{\lambda} I_{b \lambda}-\beta_{\lambda} I_{\lambda}+\frac{\sigma_{s \lambda}}{4 \pi} \int_{4 \pi} I_{\lambda}\left(\hat{s}_{i}\right) \phi_{s \lambda}\left(\hat{s}_{i}, \hat{s}\right) d \Omega_{i}
$$

where $\beta_{\lambda}$ is the extinction coefficient, which is equivalent to the sum of absorption and scattering coefficients. It is challenging to solve Eq. 5 due to its directional nature, even for 1D cases.

Methods like Spherical Harmonics (or $\mathrm{P}_{\mathrm{N}}$ ), Discrete-Ordinates (or $\mathrm{S}_{\mathrm{N}}$ ), Monte-Carlo, and Zonal are used to solve Eq. 5 that provide approximate solutions. ${ }^{23}$ The Spherical Harmonics (or $\mathrm{P}_{\mathrm{N}}$ ) method converts Eq. 5 into a set of simultaneous partial differential equations (PDE). The $\mathrm{P}_{\mathrm{N}}$ method expresses the radiation intensity field $I$ in terms of orthogonal basis functions and spherical coordinate system. ${ }^{24}$ In the $\mathrm{P}_{\mathrm{N}}$ method, $I(r, \hat{s})$ at any location $r$ is assumed to be the values of a scalar function on the surface of a sphere of unit radius around point $r$. The scalar function is expressed as

$$
I(r, \hat{s})=\sum_{l=0}^{\infty} \sum_{m=-l}^{l} I_{l}^{m}(r) Y_{l}^{m}(\hat{s})
$$

where $I_{l}^{m}(r)$ are coefficients based on the position and $Y_{l}^{m}(\hat{s})$ are spherical harmonics which are defined as

$$
Y_{l}^{m}(\hat{s})=(-1)^{(m+|m|) / 2}\left[\frac{(l-|m|) !}{(l+|m|) !}\right]^{1 / 2} e^{i m \psi} P_{l}^{|m|}(\cos \theta)
$$

where $\theta$ and $\psi$ are polar and azimuthal angles defining the direction unit vector $\hat{s}$, and $P_{l}^{m}$ are associated with Legendre polynomials. The scattering function is also expressed in the form of Legendre Polynomials as

$$
\phi_{s}\left(\hat{s}_{i}, \hat{s}\right)=\sum_{m=0}^{M} A_{j} P_{j}\left(\hat{s}_{i}\right) P_{j}(\hat{s})
$$


where $M$ is the order of approximation for the phase function. The $\mathrm{P}_{1}$ approximation to the RTE is obtained when the terms in Eq. 6 is restricted until $l=1$. The resulting PDE is a function of variable $G$, which is the total intensity acting on a point from all directions and is defined as:

$$
G(r)=\int_{4 \pi} I(r, \hat{s}) d \Omega
$$

Applying the $\mathrm{P}_{1}$ approximation to Eq. 5 results in

$$
\nabla \cdot q_{\lambda}=\kappa_{\lambda}\left(4 \pi I_{b \lambda}-G_{\lambda}\right)
$$

where $q_{\lambda}$ represent spectral radiative heat flux and is defined as

$$
q_{\lambda}(r)=\int_{4 \pi} I(r, \hat{s}) \hat{s} d \Omega
$$

Additionally, multiplying the Eq. 10 with $Y_{l}^{m}$ results in another relation defined as

$$
\nabla G_{\lambda}=-3 \beta_{\lambda} q_{\lambda}
$$

A Helmholtz equation is formed by combining Eqs. 10 and 12 and is solved for $G_{\lambda}$ which is given as:

$$
\nabla \cdot\left(-\frac{1}{3 \beta_{\lambda}} \nabla G_{\lambda}\right)=\kappa_{\lambda}\left(4 \pi I_{b \lambda}-G_{\lambda}\right)
$$

It should be noted that the $\mathrm{P}_{1}$ method is a second-order elliptic PDE that is easy to integrate and less complicated when compared to other approximate methods. The $\mathrm{P}_{1}$ method handles scattering media but is inaccurate when the medium is optically thin. ${ }^{23,24}$

A Marshak boundary condition ${ }^{25,26}$ is applied for RTE at boundaries:

$$
q_{\lambda} \cdot \hat{n}=\frac{\epsilon}{2(2-\epsilon)}\left(4 \pi I_{b \lambda}-G_{\lambda}\right)
$$

where $\hat{n}$ represents the normal vector and $\epsilon$ represents the emissivity of the material.

\section{II.B. Solution procedure}

The general form energy equation from Eq. 1 for a heat conduction problem is given as:

$$
\rho_{s} c_{p} \frac{\partial T}{\partial t}=\nabla \cdot k_{\mathrm{eff}} \nabla T
$$

where $\rho_{s}$ is the total solid density of the material, $c_{p}$ is specific heat capacity of solid, $T$ is the temperature, $t$ is time, and $k_{\text {eff }}$ is the effective thermal conductivity. The heat conduction through the solid material solved by using Eq. 15 is referred as "pure conduction" in this work. The effective thermal conductivity takes into account the thermal conductivities of solid, gas, as well as radiation. However, the values of $k_{\text {eff }}$ are accurate in an optically thick and isotropic medium, where the approximations leading to radiative conductivity are valid. Though the approximation of optically thick medium stands valid, the assumption of the medium's isotropic nature does not stand true at large local temperature gradients. The most common situations where large temperature gradients occur are during arc-jet and radiant heating tests. Also, the value of $k_{\text {eff }}$, especially for low-density ablators, is often under-predicted, thus suppressing the radiation energy transport by scattering and absorption. ${ }^{27}$ Therefore, a coupled approach between heat conduction and RTE is used. Also, $k_{\text {eff }}$ accounts for the total radiative heat transfer, whereas the coupled approach can be used to simulate the spectral radiative heat transfer within the material. The energy equation for the coupled approach is of the form:

$$
\rho_{s} c_{p} \frac{\partial T}{\partial t}=\nabla \cdot\left(k_{s / g} \nabla T+q_{\mathrm{rad}}\right)=\nabla \cdot\left(k_{s / g} \nabla T\right)+\nabla \cdot q_{\mathrm{rad}}
$$


where $k_{s / g}$ is the thermal conductivity that takes into account the contributions of solid and gas phase, and $q_{\text {rad }}$ is the total radiative heat flux through the solid. The heat conduction through the solid material solved by using Eq. 16 is referred as "conduction coupled with radiative emission" in this work. It can be seen that Eq. 16, when compared to Eq. 15, has an additional term. While coupling the heat conduction and RTE, the extra term $\nabla \cdot q_{\text {rad }}$ is added into source term vector $\mathbf{S}$ of Eq. 1 . The total radiative flux is calculated as

$$
\nabla \cdot q_{\mathrm{rad}}=\int_{\lambda} \nabla \cdot q_{\lambda} d \lambda=\int_{\lambda} \kappa_{\lambda}\left(4 \pi I_{b \lambda}-G_{\lambda}\right) d \lambda
$$

At each time step, Eq. 13 is solved for $G_{\lambda}$ by using the temperature distribution. Since Eq. 13 represents spectral properties, the number of equations solved at each cell center is equivalent to the chosen wavelength intervals. The net emission is then calculated using Eq. 17, and Eq. 16 is solved with $\nabla \cdot q_{\text {rad }}$ inserted into it. With the new temperature distribution as the output, Eq. 13 solve for new $G_{\lambda}$. This process is repeated until the difference between the temperature distributions, for the successive iterations, is below the prescribed tolerance.

\section{Results and Discussions}

\section{III.A. Verification}

Verification is performed by comparing the numerical solution to the analytical one. To do so, all the parameters, except $G_{\lambda}$, are assumed as constants $\left(\kappa_{\lambda}=1, \beta_{\lambda}=1 / 3\right.$, and $\left.I_{b \lambda}=1 / 4 \pi\right)$ in Eq. 13 . A $1 \mathrm{D}$ domain is considered that turns the Eq. 13 to an ordinary differential equation. The results from the verification ensure the correctness of the code with RTE added. The verification is also performed by running the KATS for multiple processors, and it is seen that the numerical results computed by KATS match the analytical solution very well, as shown in Fig. 1.

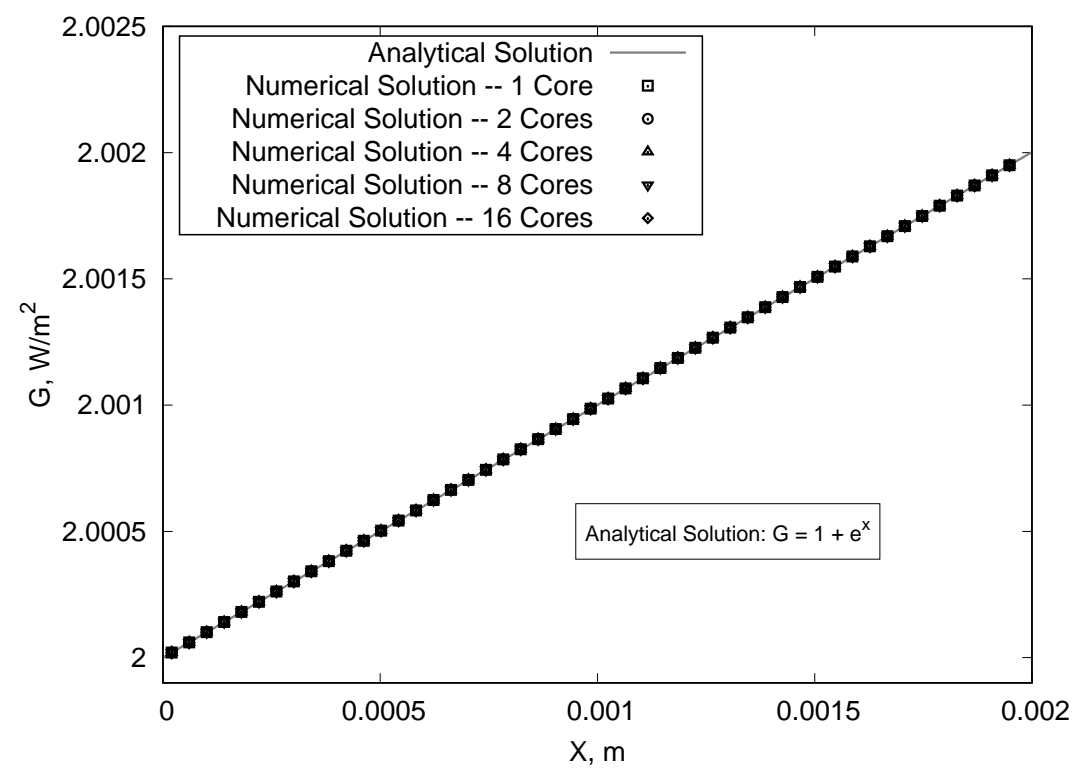

Figure 1. Verification results

\section{III.B. Validation}

The validation for this coupling scheme is performed by comparing the temperature profiles of pure conduction and conduction coupled with emission simulations. Since Eq. 15 and Eq. 16 refer to the heat transfer 
through the same solid, for a total heat flux at the heating surface, both the simulations should report the same results. The total heat flux boundary condition can be in the form of a temperature profile or a heat flux profile at the surface. When the relative error between the temperature profiles simulated by two methods is within the error margin of $10 \%$, then the coupling scheme is treated as accurate.

The material used for all the validation cases is LI-900. The thermal conductivity (both $k_{\text {eff }}$ and $k_{s+g}$ ), absorption, and extinction coefficients for LI-900 are taken from Marschall et al. ${ }^{28}$ The specific heat and density of LI-900 are taken from Williams et al. ${ }^{29} \mathrm{~A}$ wavelength range from $0.1 \mu \mathrm{m}$ to $100 \mu \mathrm{m}$ is considered, and 101 wavelength intervals are chosen for the simulations under the validation section. The simulations solve the energy equation only.

\section{III.B.1. Marschall et al. ${ }^{28}$ Test Cases}

Marschall et al. ${ }^{28}$ test cases include a set of three 1D cases: radiant heating, arc-jet heating, and space shuttle entry. In these test cases, the sample is heated by applying a varying temperature profile at the heating surface as a function of time. A validation study is conducted by comparing the temperature profile computed using pure conduction and conduction coupled with radiative emission for each test case. Since a fixed temperature exists at the boundaries, the profiles should be almost the same.

\section{III.B.1.1 Radiant heating}

For the radiant heating test, a $1.25 \mathrm{~cm}$ sample is heated. The pressure at the heating surface is of 1 atmosphere, and the temperature increases from $256 \mathrm{~K}$ to $1228 \mathrm{~K}$ in 15 seconds and remains constant for the rest of the heating time. The temperature at the back face of the sample is kept at $256 \mathrm{~K}$ for the whole heating.

The results from the simulation of the radiant heating case are illustrated in Fig. 2. Figure 2(a) shows the temperature profiles at different points for pure conduction and conduction coupled with radiation emission. The difference between the temperature profiles calculated from both the methods is shown in Fig. 2(b). The difference shows that the relative error between the two methods is below $4 \%$.

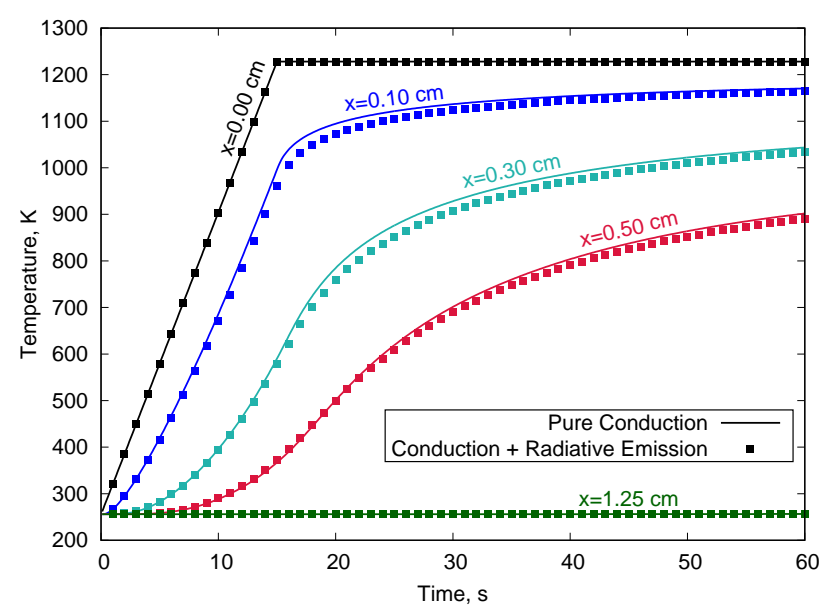

(a) Temperature profiles at various locations within the sample

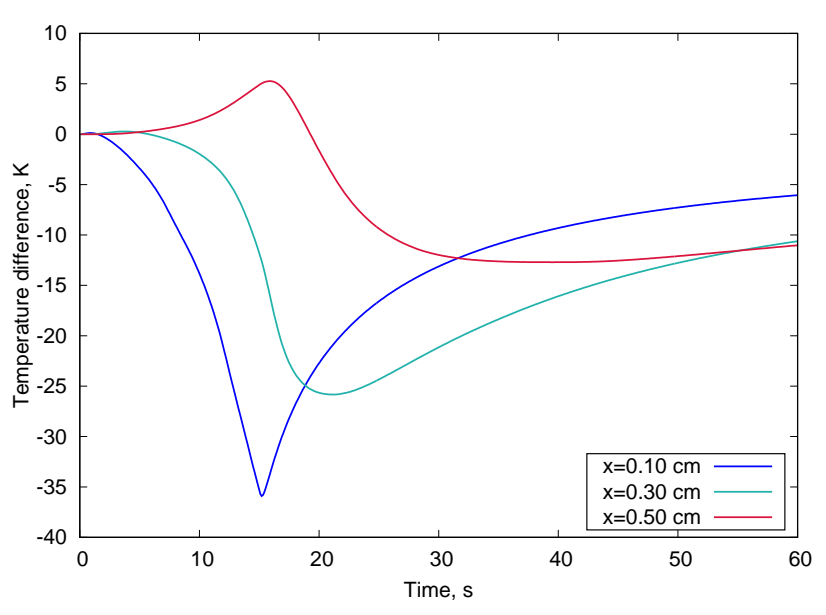

(b) Temperature difference between two methods

Figure 2. Comparison between pure conduction and conduction coupled with radiative emission for radiant heating case

\section{III.B.1.2 Arc-jet heating}

The second case is the arc-jet heating test on a $4 \mathrm{~cm}$ sample. While the sample's back face is impermeable and adiabatic, the front surface is at a pressure of 0.01 atmosphere and is heated, increasing the temperature from $300 \mathrm{~K}$ to $1700 \mathrm{~K}$ in 5 seconds, remaining at $1700 \mathrm{~K}$ for another 3 minutes, and then following a cooling curve. 
The results from the simulation of the arc-jet heating case are given in Fig. 3. Figure 3(a) shows the temperature profiles for both pure conduction and conduction coupled with radiative emission at different points on the sample. The difference between the temperature profiles calculated from both the methods is shown in Fig. 3(b). The difference shows that the relative error between the two methods is below $10 \%$.

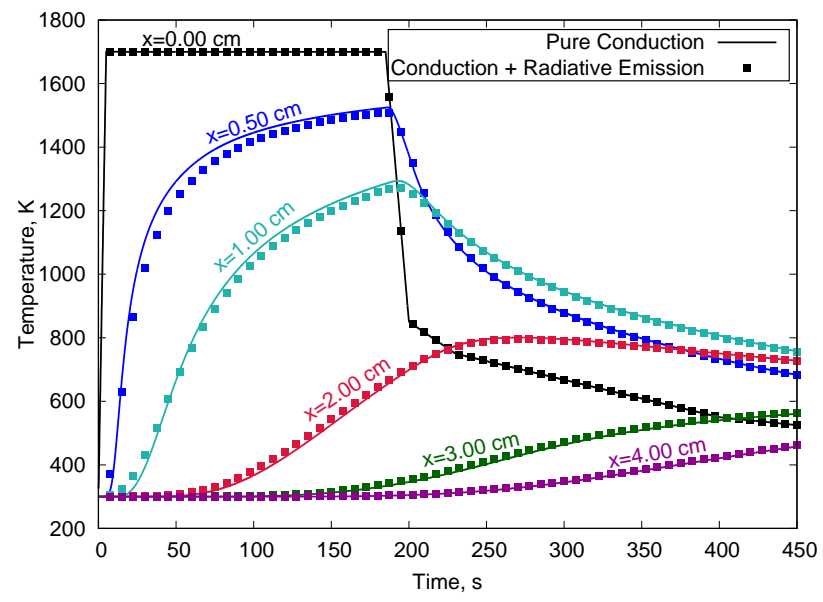

(a) Temperature profiles at various locations within the sample

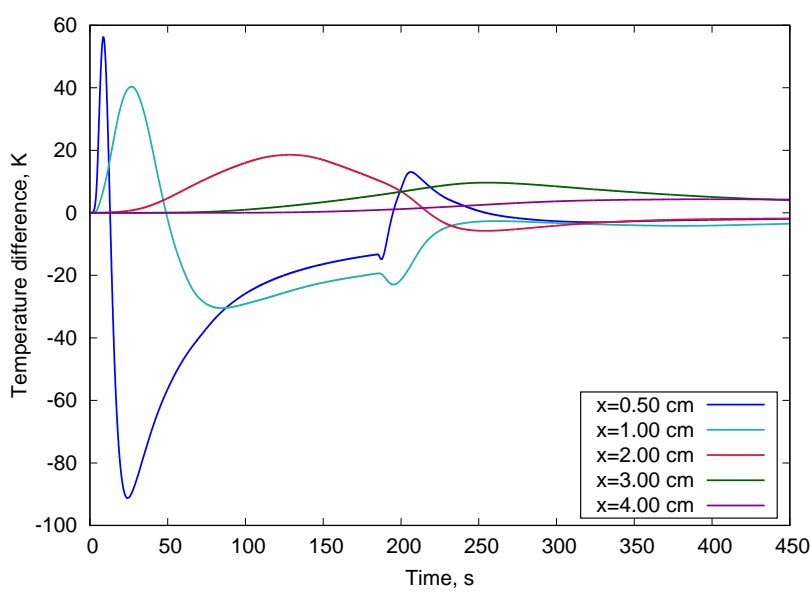

(b) Temperature difference between two methods

Figure 3. Comparison between pure conduction and conduction coupled with radiative emission for arc-jet heating case

\section{III.B.1.3 Space shuttle entry}

The third case is the space shuttle on a $5 \mathrm{~cm}$ sample. The front surface at $300 \mathrm{~K}$ and 0.1 atmosphere is heated to $1200 \mathrm{~K}$ for 350 seconds, remaining at $1200 \mathrm{~K}$ for another 11 minutes. The front surface later undergoes a transient temperature profile as shown in Fig. 4(a). The back surface of the sample is set to be adiabatic and impermeable. The results from the simulation of the space shuttle entry case are shown in Fig. 4. Figure 4(a) shows the temperature profiles for both pure conduction and conduction coupled with radiative emission at different points on the sample. The difference between the temperature profiles calculated from both the methods is shown in Fig. 4(b). The relative error between the two methods is below $2 \%$, and the closeness of the temperature profiles can be seen in Fig. 4(a).

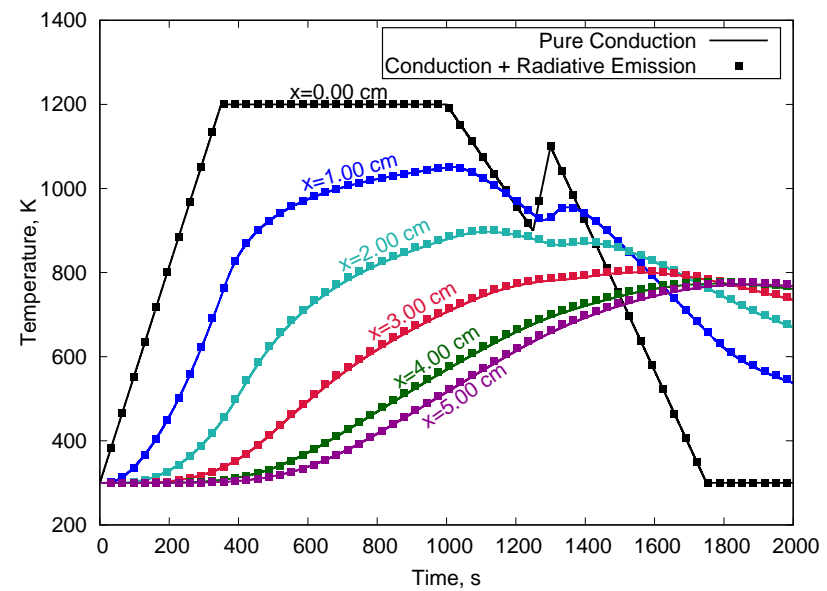

(a) Temperature profiles at various locations within the sample

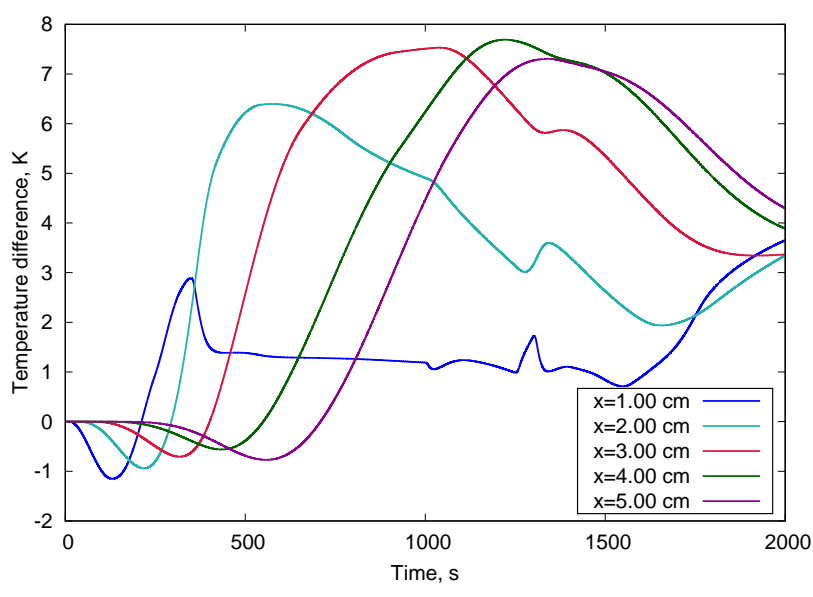

(b) Temperature difference between two methods

Figure 4. Comparison between pure conduction and conduction coupled with radiative emission for space shuttle entry case

It should be noted that the solutions as shown in Figs. 2, 3, 4 are similar when compared to those of 
Marschall et al. ${ }^{28}$ and the relative error in temperatures between pure conduction and conduction coupled with radiative emission are below $10 \%$.

\section{III.B.2. 3D Block}

The validation is performed on a Block mesh whose dimensions are $1.25 \mathrm{~cm}, 0.625 \mathrm{~cm}$, and $0.2 \mathrm{~cm}$ in x-, y-, and z-direction, respectively. The mesh of the 3D block is presented in Fig. 5.

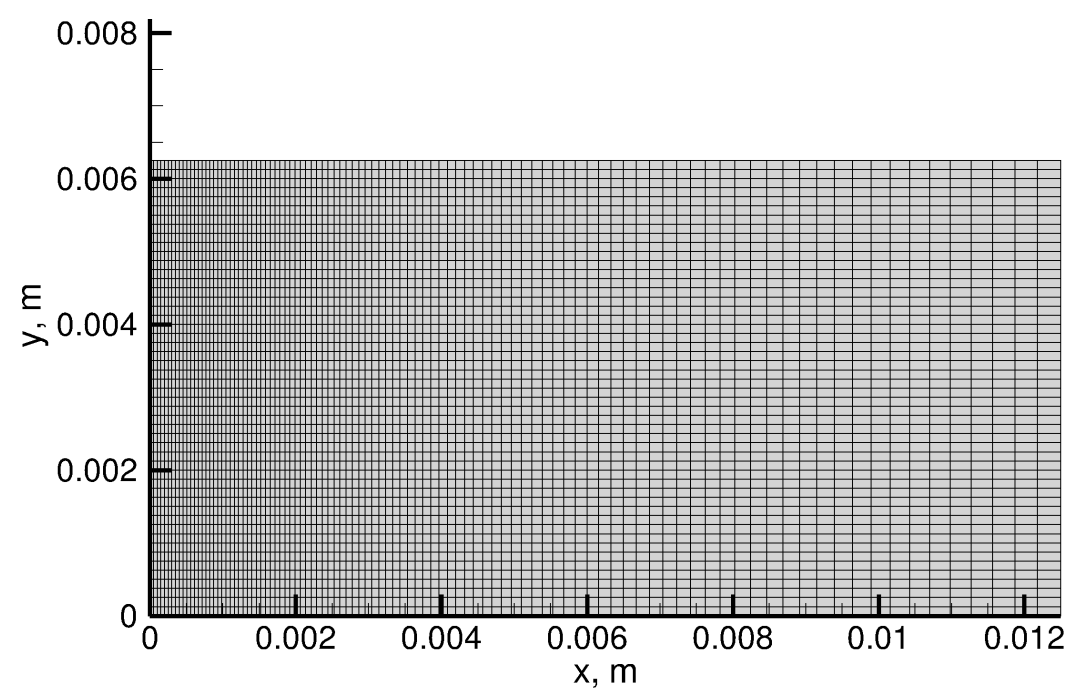

Figure 5. Mesh of 3D Block geometry

The boundary conditions for the radiant heating case, as given in Section III.B.1.1, are applied to the 3D Block mesh. Figure 6 shows the temperature and radiation source term contours for pure conduction as well as conduction coupled with radiative emission at the end of heating time. It can be seen that the temperature contours for both methods are visibly identical. The radiation source term increases along the sample length and is maximum at the location where the relatively cold surface is receiving the heat, as illustrated in Fig. 6(c).

The temperature profiles and differences between them for the two methods, as a function of time, are plotted and presented in Fig. 7. The profiles are taken along x-direction at $y=0.3 \mathrm{~cm}$ and $z=0.15 \mathrm{~cm}$. It can be observed that the profiles of the temperature match well, and the relative error between the two methods is below 10\%. These profiles are also similar to the 1D case shown in Figure 2.

\section{III.B.3. IsoQ sample}

A 2D IsoQ sample is considered for performing validation. The sample's surface is heated from $300 \mathrm{~K}$ and 1 atmosphere to a non-uniform temperature profile in 5 seconds and remains constant for the rest of the heating time. An adiabatic and impermeable condition is set for the back surface. The mesh used for the simulation and the non-uniform temperature profile is presented in Fig. 8. The temperature profile is the modified version of a steady profile that the IsoQ sample achieves when exposed to a uniform heat flux of $7.5 \times 10^{5} \mathrm{~W} / \mathrm{m}^{2}$ for a longer time.

The temperature contours and radiation source term contours at the end of the heating time are shown in Fig. 9 for the IsoQ sample. The temperature contours are visibly similar for the two methods. The radiation source term is in the form of a patch across the region where the relatively colder surface is receiving the heat, as can be seen in Fig. 9(c).

The temperature profiles at different thermocouple (TC) locations and differences in the temperature between the two methods are illustrated in Fig. 10. The TC locations are given in Table 1. Figures 10(a) and (b) represent the temperature profiles for thermocouples along the stagnation line and along the shoulder, respectively. The temperature profiles for both methods match well, and it is observed that the relative error between the temperature profiles is below $4 \%$. 


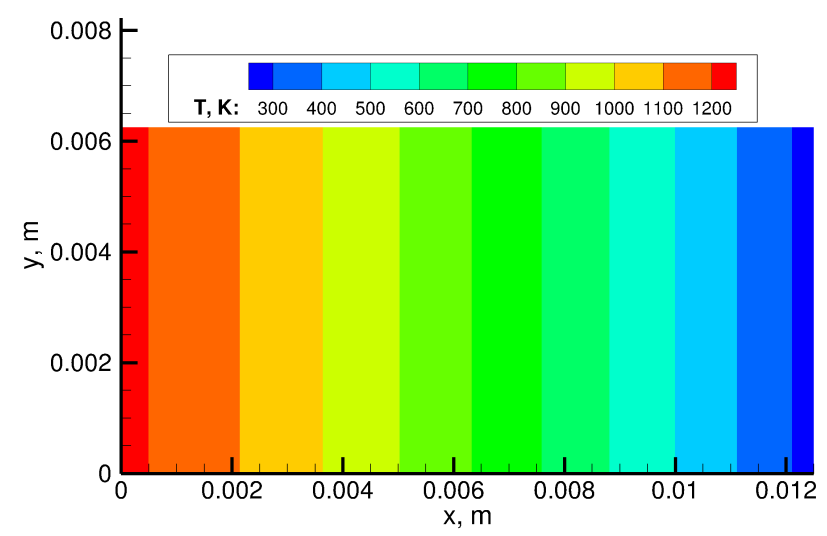

(a) Temperature contour for pure conduction

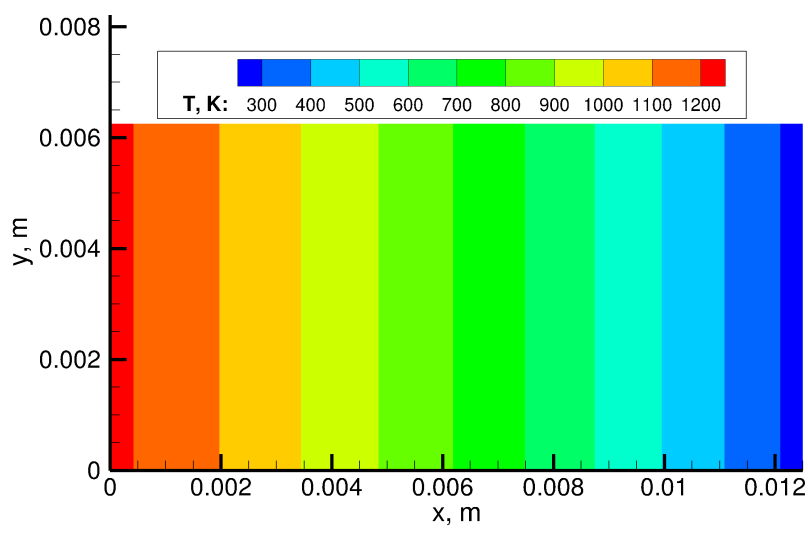

(b) Temperature contour for conduction coupled radiative emission

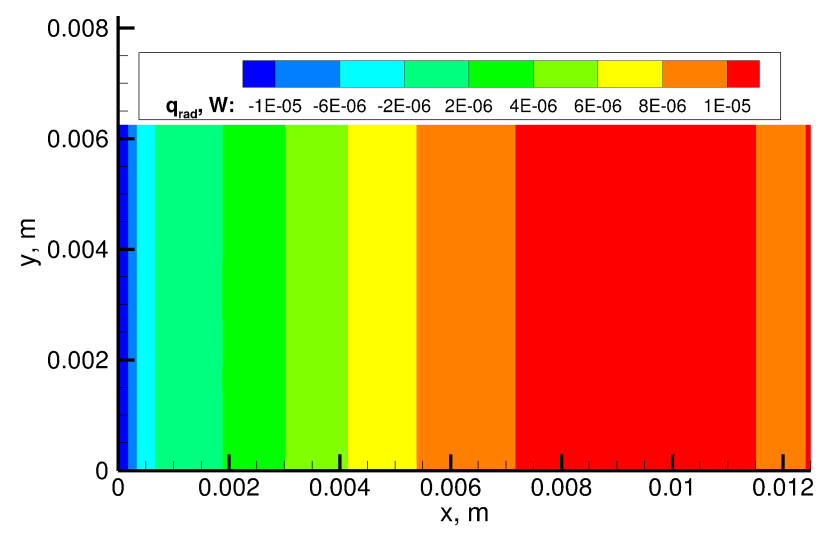

(c) Radiation source term

Figure 6. Temperature and Radiation source term contours for pure conduction and conduction coupled radiative emission for $3 \mathrm{D}$ Block case at the end of heating time

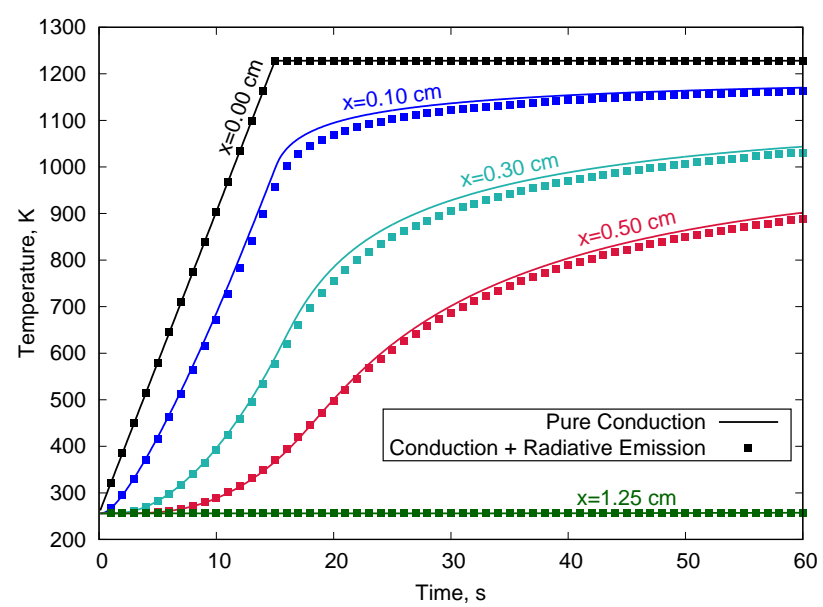

(a) Temperature profiles at various locations within the sample

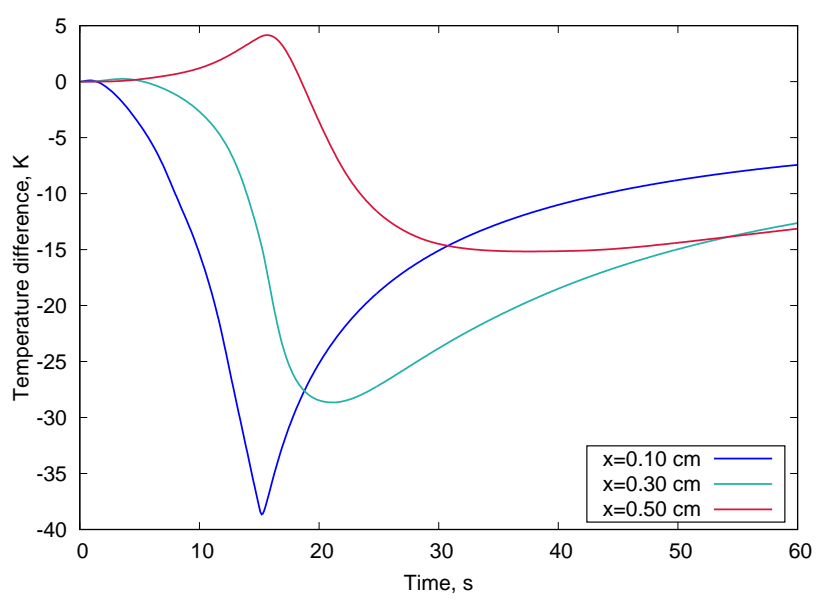

(b) Temperature difference between two methods

Figure 7. Comparison between pure conduction and conduction coupled with radiative emission for 3D Block case 


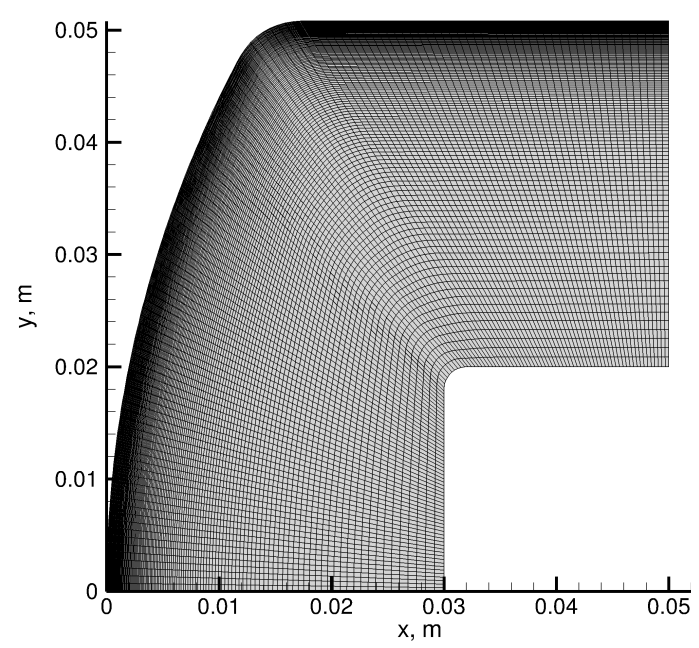

(a) 2D Mesh of IsoQ sample

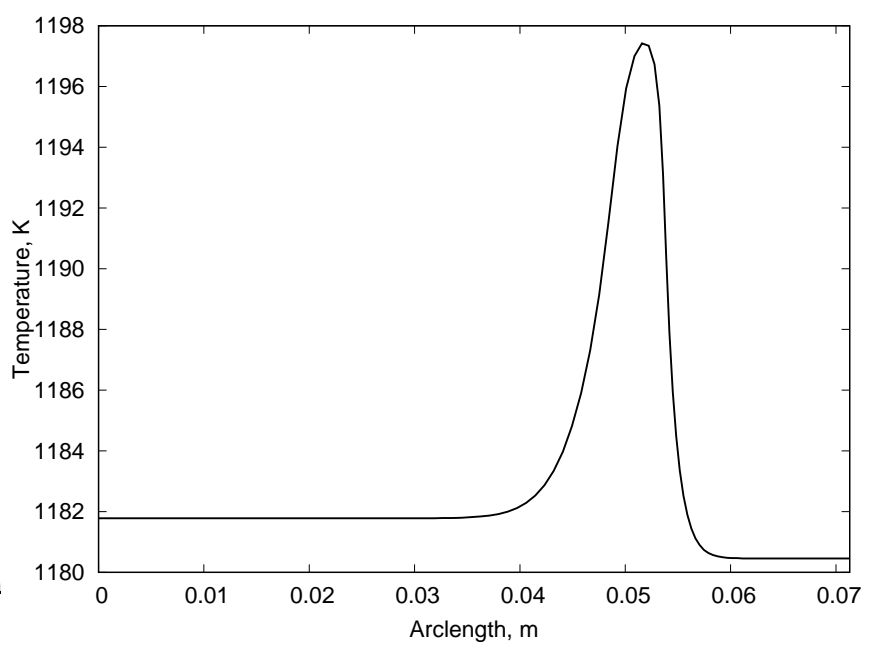

(b) Temperature profile at the surface

Figure 8. Mesh and Non-uniform Temperature profile at the surface of IsoQ sample

Table 1. Virtual Thermocouple locations for IsoQ sample

\begin{tabular}{cc}
\hline \hline TC\# & Coordinates, $\mathrm{m}$ \\
\hline 1 & $(0.00000,0.00000,0.0)$ \\
2 & $(0.00381,0.00000,0.0)$ \\
3 & $(0.00762,0.00000,0.0)$ \\
4 & $(0.01143,0.00000,0.0)$ \\
5 & $(0.01542,0.00000,0.0)$ \\
6 & $(0.02286,0.02540,0.0)$ \\
7 & $(0.02286,0.03810,0.0)$ \\
8 & $(0.02286,0.04445,0.0)$ \\
9 & $(0.03048,0.04445,0.0)$ \\
\hline \hline
\end{tabular}




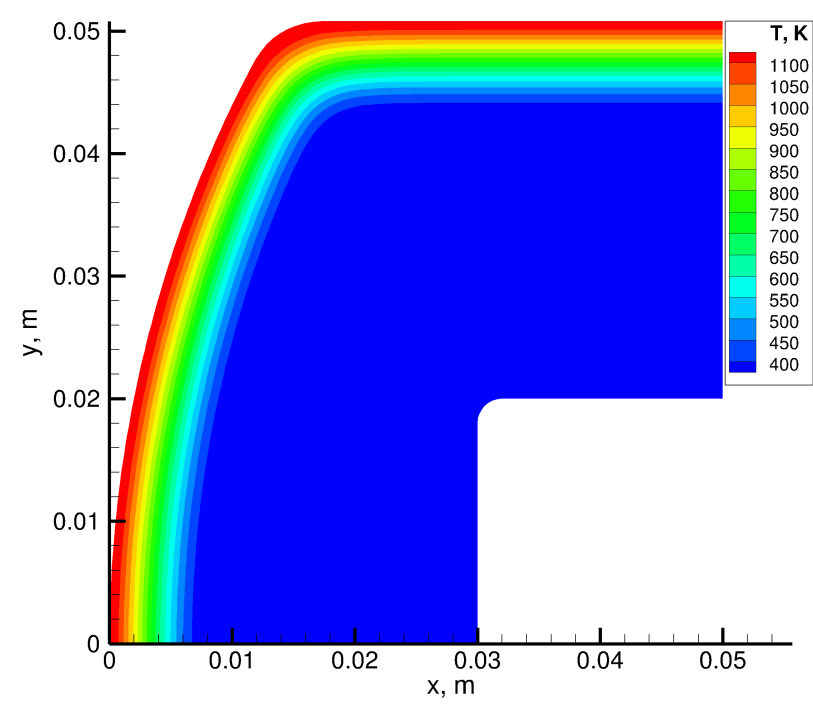

(a) Temperature contour for pure conduction

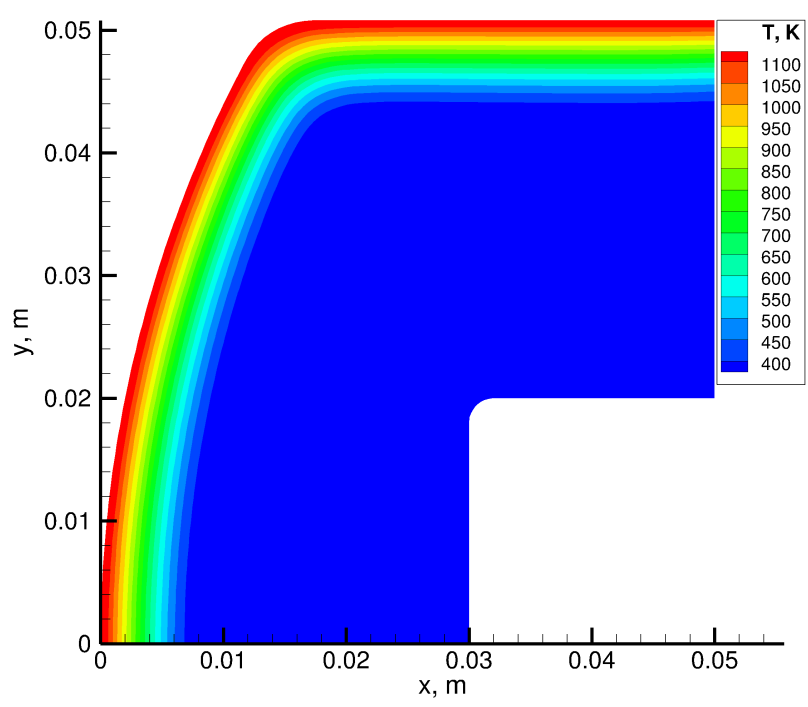

(b) Temperature contour for conduction coupled radiative emission

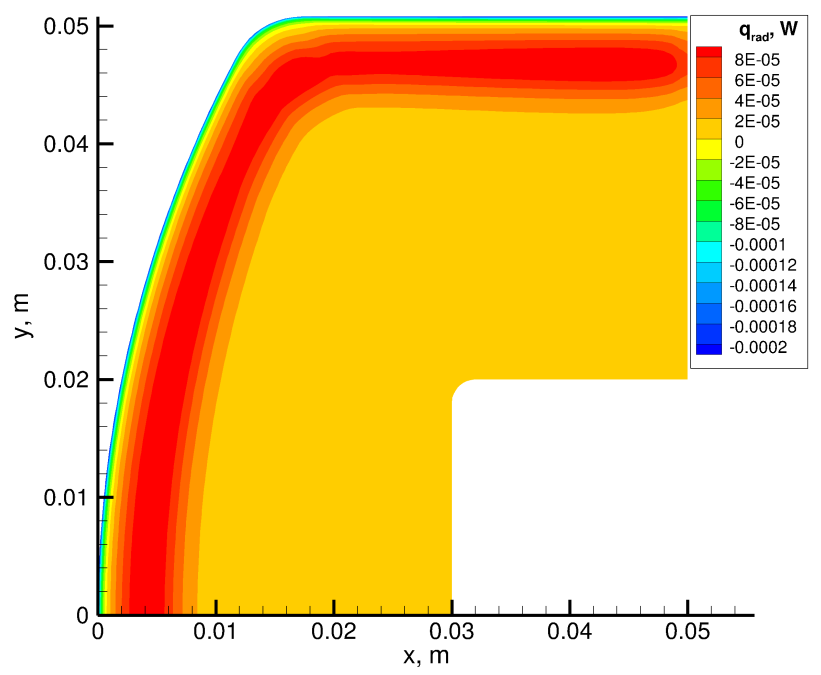

(c) Radiation source term

Figure 9. Temperature and Radiation source term contours for pure conduction and conduction coupled radiative emission for IsoQ sample at the end of heating time 

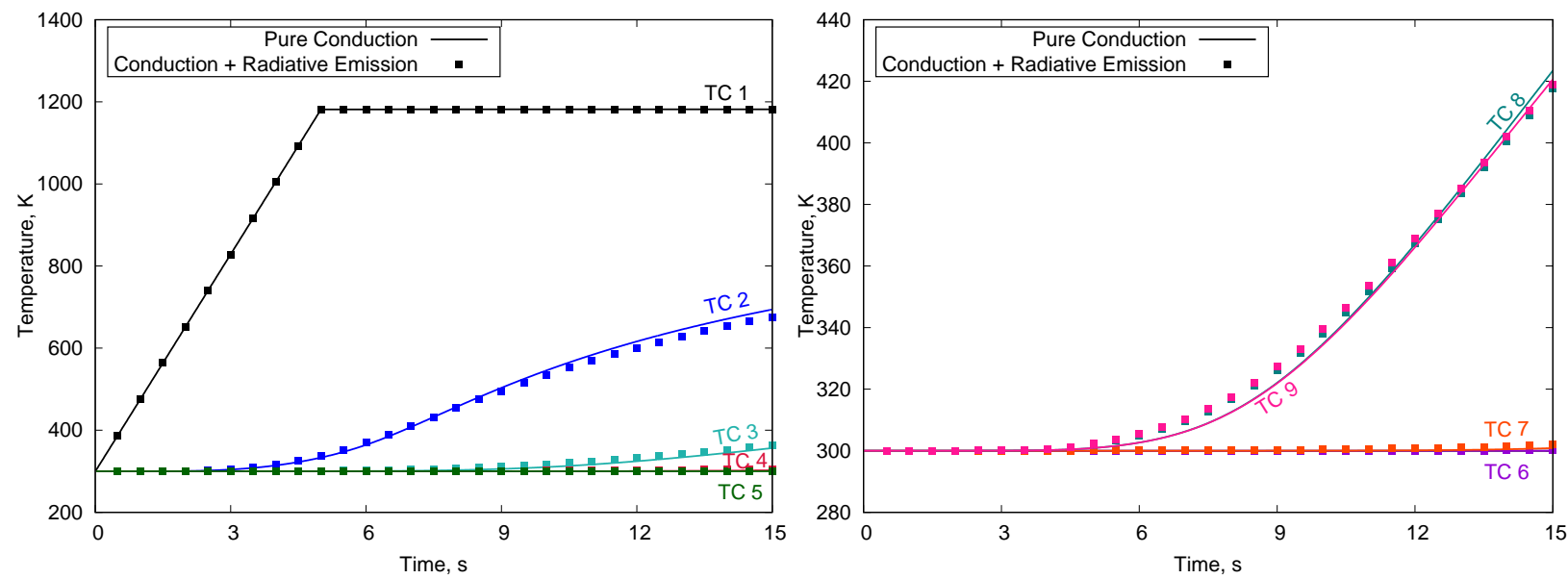

(a) Temperature profiles at various locations within the sample (b) Temperature profiles at various locations within the sample (TC\# 1- 5) (TC\# 6-9)

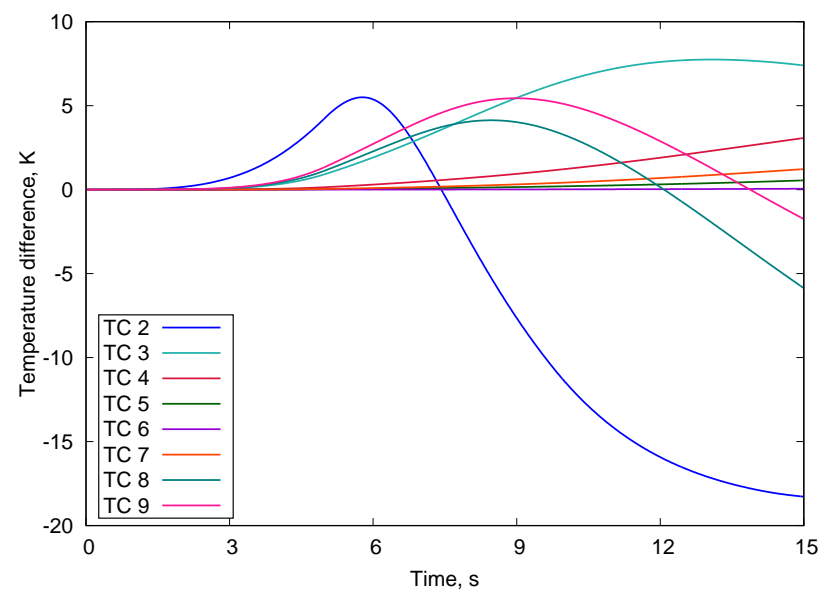

(c) Temperature difference between two methods

Figure 10. Comparison between pure conduction and conduction coupled with radiative emission for IsoQ sample 


\section{III.B.4. Stardust Return Capsule}

The coupling scheme is applied to the Stardust sample return capsule (SRC) heat shield. A non-uniform temperature profile is given as the boundary condition at the heating surface. The heating starts at $298 \mathrm{~K}$ and 0.01 atmosphere and increases linearly to the respective temperature profile in 8 seconds and remains constant after that. The back surface is set to be adiabatic and impermeable. A modified version of Stardust mesh is considered ${ }^{22}$ for the simulation, which is illustrated in Fig. 11 along with the non-uniform temperature profile. The temperature profile is the modified version of a steady profile that the Stardust capsule achieves when exposed to heat flux corresponding to $t=34 \mathrm{~s}$ of its travel. ${ }^{30}$

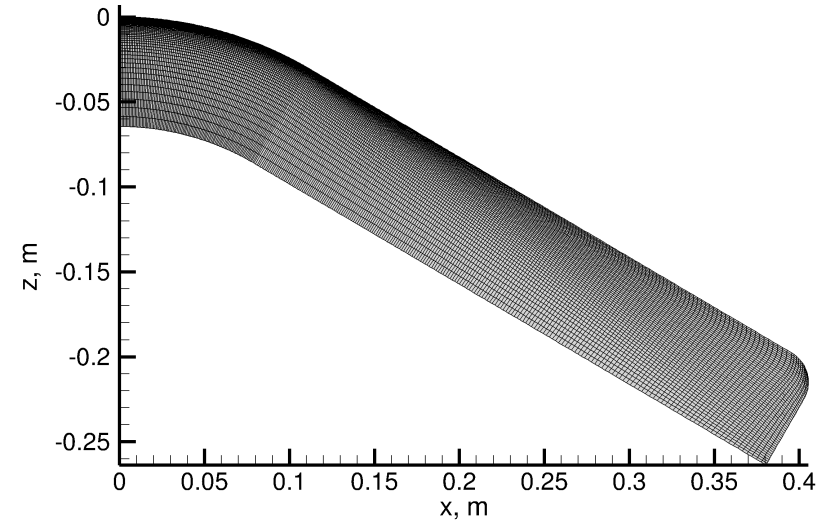

(a) Modified mesh of Stardust

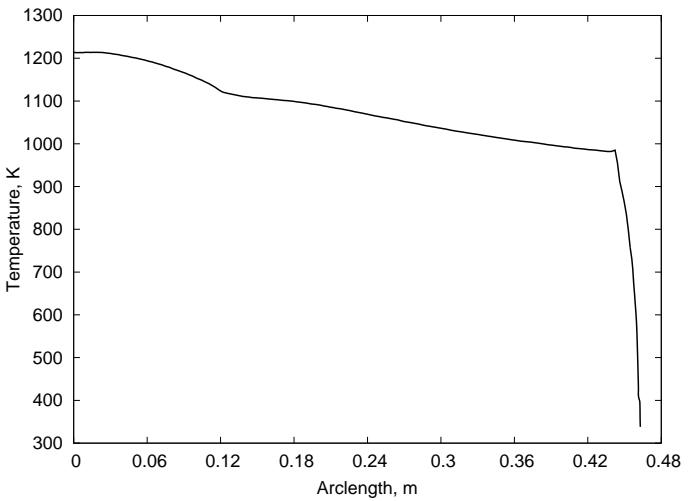

(b) Temperature profile at the surface

Figure 11. Modified Mesh and Non-uniform Temperature profile at the surface of Stardust heat shield

The temperature contours and radiation source term contours at the end of heating time are presented in Fig. 12. The temperature contours appear visibly similar for both methods. Figure 12(c) shows the contour of the radiation source term, which is higher near the shoulder location.

Figure 13 illustrates the temperature profiles and difference in temperature between the methods as a function of heating time for various thermocouple (TC) locations. The TC locations considered are given in Table 2. The temperature profiles for TC's along the stagnation line and along the shoulder are represented in Fig. 13(a) and (b), respectively. The temperature profiles match well for the two methods, with the relative error between them being around $10 \%$.

Table 2. Virtual Thermocouple locations for Stardust entry capsule

\begin{tabular}{cc}
\hline \hline TC\# & Coordinates, $\mathrm{m}$ \\
\hline 1 & $(0.0000,0.0,0.0000)$ \\
2 & $(0.0000,0.0,-0.0020)$ \\
3 & $(0.0000,0.0,-0.0040)$ \\
4 & $(0.0000,0.0,-0.0080)$ \\
5 & $(0.0000,0.0,-0.0300)$ \\
6 & $(0.1969,0.0,-0.0899)$ \\
7 & $(0.2861,0.0,-0.1425)$ \\
8 & $(0.3753,0.0,-0.1950)$ \\
\hline \hline
\end{tabular}

It can be seen from the validation study that temperature profiles (both uniform and non-uniform) were given as boundary conditions at the heating surface. When a heat flux is given as a boundary condition, the heating surface temperatures extrapolated from the heat conduction equation are different for the two methods. Since Eq. 13 is a boundary-value problem, different temperatures at the boundary would result in different solutions. This results in a significant difference in temperature profiles simulated by two methods. A further investigation needs to be performed to understand and resolve this issue. 

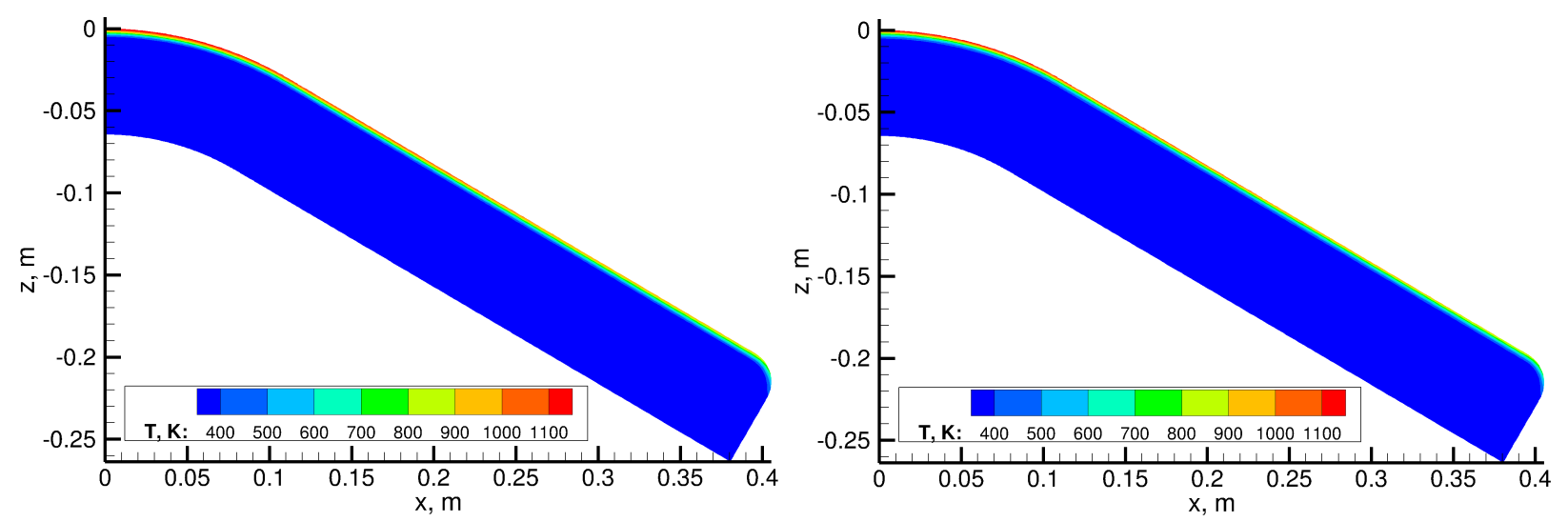

(a) Temperature contour for pure conduction

(b) Temperature contour for conduction coupled radiative emission

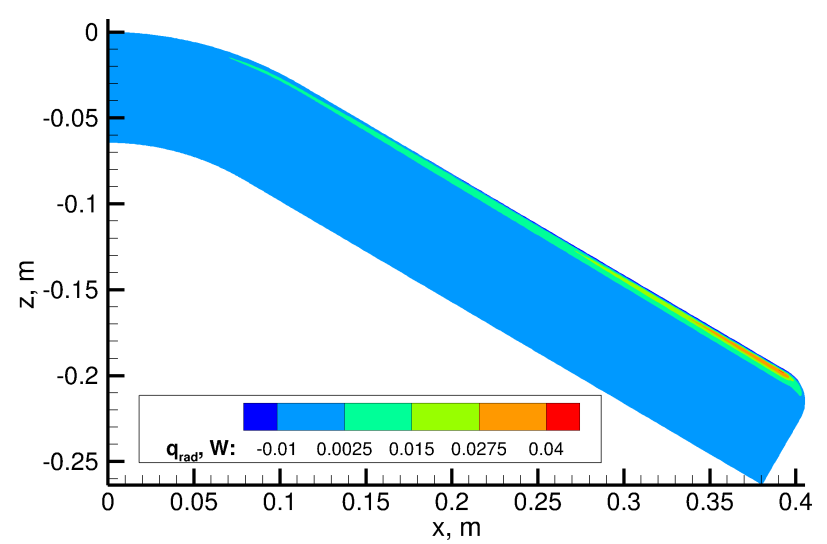

(c) Radiation source term

Figure 12. Temperature and Radiation source term contours for pure conduction and conduction coupled radiative emission for Stardust entry capsule at the end of heating time 

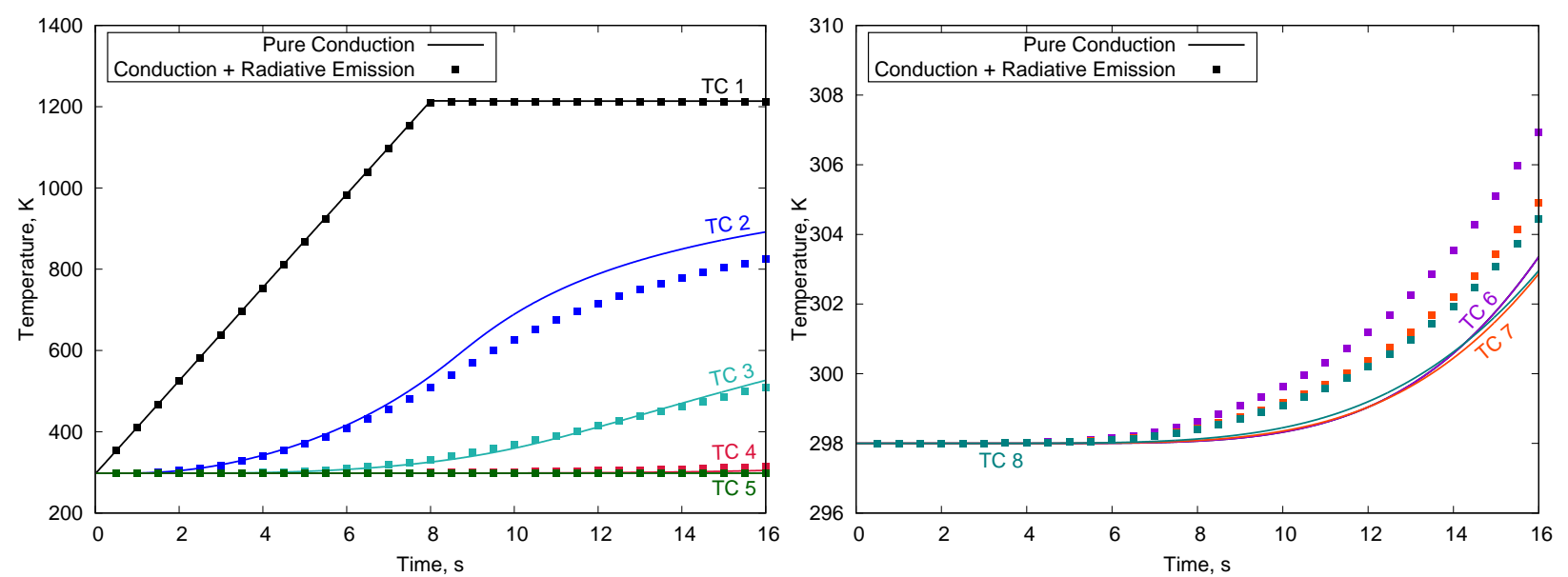

(a) Temperature profiles at various locations within the sample (b) Temperature profiles at various locations within the sample (TC\# 1-5)

(TC\# 6-8)

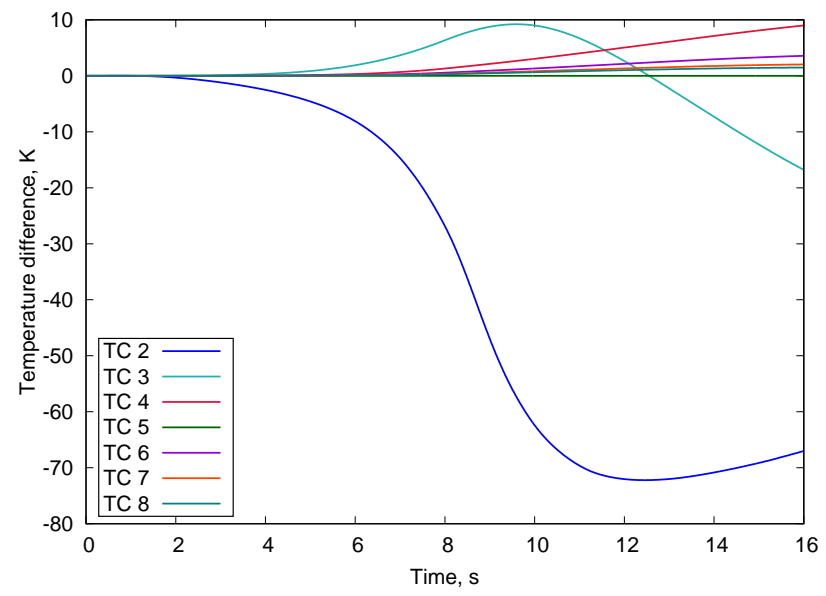

(c) Temperature difference between two methods

Figure 13. Comparison between pure conduction and conduction coupled with radiative emission for Stardust entry capsule 
It should also be noticed that the temperature profiles of the heating surface for all cases except the arc-jet heating case (Section III.B.1.2) were around $1200 \mathrm{~K}$. The values for $k_{s / g}$ of LI-900 were derived numerically through calibration by Marschall et al. ${ }^{28}$ At certain temperature and pressure, $\nabla \cdot q_{\mathrm{rad}}$ is calculated and $k_{s / g}$ is determined by comparing with pure conduction values. However, it was found that the uncertainty of these calibrated values increased with an increase in temperature. The good examples to showcase this uncertainty are the Marschall et al. ${ }^{28}$ cases. The heating temperature profile was around $1200 \mathrm{~K}$ for radiant heating and space shuttle entry cases, and the relative error was below $4 \%$ between the methods as can be seen in Sections III.B.1.1 and III.B.1.3. However, for the arc-jet heating case, the front surface's temperature profile goes up to $1700 \mathrm{~K}$, and it can be observed from Fig. 3 that the relative error between the simulation results of the two methods reach around $10 \%$. Therefore, the temperature profiles of the heating surface were limited to around $1200 \mathrm{~K}$ for Block, IsoQ, and Stardust cases to avoid huge discrepancies in the coupling scheme for this work. However, $k_{s / g}$ values will be recalibrated to more accurate values, and the simulations will be run at higher temperature profiles in the future.

\section{III.C. Laser Ablation}

Laser heating simulations are performed mimicking the experiments conducted by White ${ }^{6}$ to understand the spectral contribution of the radiative heat flux. White ${ }^{6}$ used Fiber and $\mathrm{CO}_{2}$ lasers of wavelengths $1.07 \mu \mathrm{m}$ and $10.6 \mu \mathrm{m}$, respectively, for heating various charring fibrous materials. The samples were exposed to lasers for 30 seconds at a constant heat flux of $115 \mathrm{~W} / \mathrm{cm}^{2}$. The material used for the simulation is TACOT, a fictitious material that replicates the behavior of PICA. ${ }^{31}$ However, the optical properties of the material are assumed to be the one of LI-900 material. Therefore, the material in total is a combination of two different material properties. It is to be noted that though this amalgamated material does not exist, it is expected that the behavior observed would be a general trend.

A sample of length $2 \mathrm{~cm}$ is considered. Three simulations were run: one with pure conduction and the other two with conduction coupled with radiative emission for both the laser wavelengths. Since the available thermal conductivity table for TACOT was that of $k_{\text {eff }}$, the coupling scheme was performed by accounting for the conduction with $k_{\text {eff }}$ and radiation with RTE but by assuming the Planck function to be zero. The simulations solve both mass and energy equations representing density decomposition and heat transfer through solid, respectively. A Neumann boundary condition at the heating surface and a Marshak boundary condition at the wall is applied for the RTE.

The temperature and solid density profiles as a function of heating time are presented in Fig. 14. The absorption and extinction coefficients $\left(\kappa_{\lambda}, \beta_{\lambda}\right)$ for $\mathrm{CO}_{2}$ laser and Fiber laser are given in Table 3. It should be noted that the $\mathrm{CO}_{2}$ laser has higher absorption and extinction coefficients compared to the Fiber laser. The higher magnitudes of these coefficients imply that the energy is absorbed within a thin layer. On the other hand, the lower values of these coefficients indicate that the energy is deposited deep inside the sample leading to a different heat transfer process. In Fig. 14(a), it can be seen that the temperature profile for pure conduction and $\mathrm{CO}_{2}$ laser is higher at the surface when compared to Fiber laser. The temperature distribution within the material for pure conduction and $\mathrm{CO}_{2}$ laser follow the same trend. However, the temperature profiles within the material irradiated by Fiber laser are higher compared to the other two cases. Since the internal temperatures are higher for the Fiber laser case, the decomposition of the solid is also higher when compared to the other two methods, as can be seen in Fig. 14(b).

\begin{tabular}{ccc} 
Table 3. Optical properties of LI-900 based on laser waveleng \\
\hline \hline Laser & Wavelength $(\lambda), \mu \mathrm{m}$ & $\left(\kappa_{\lambda}, \beta_{\lambda}\right), \mathrm{cm}^{-1}$ \\
\hline Hydrogen & 0.123 & $(99.00,177.40)$ \\
Argon Ion & 0.5145 & $(0.1627,59.83)$ \\
Fiber & 1.07 & $(0.1211,69.85)$ \\
$\mathrm{CO}$ & 5.5 & $(9.5520,45.91)$ \\
$\mathrm{CO}_{2}$ & 10.6 & $(15.18,233.20)$ \\
\hline \hline
\end{tabular}

Figure 15 shows the distribution of the temperature and solid density along the sample length at the end of the heating time. It can be observed that the internal temperature distribution for the Fiber laser is higher 


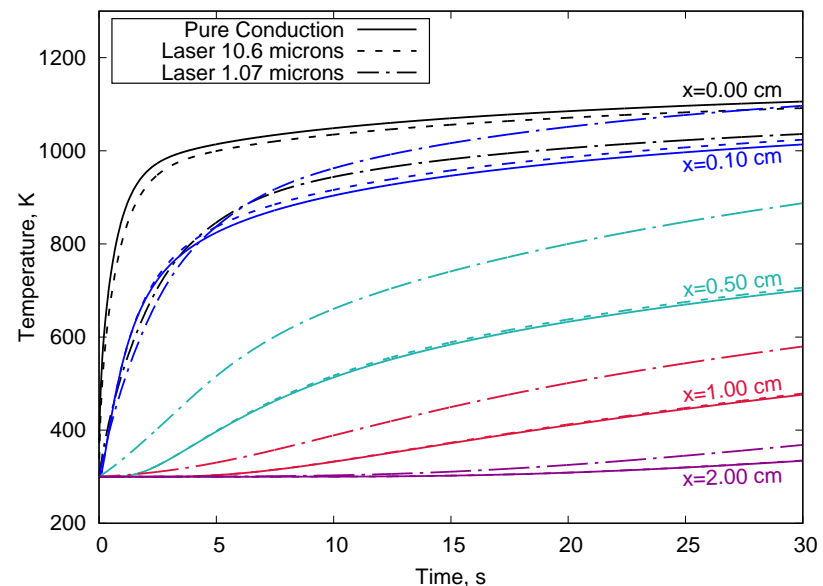

(a) Temperature profiles at various locations within the sample

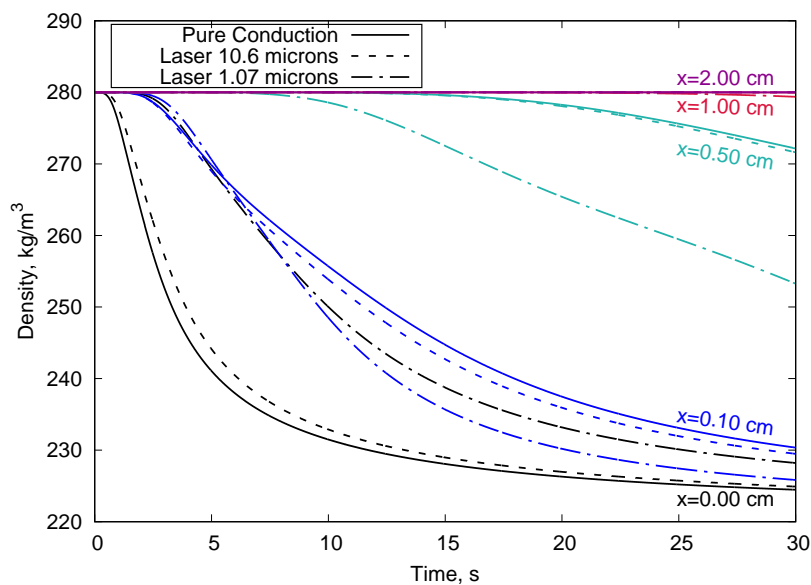

(b) Density profiles at various locations within the sample

Figure 14. Temperature and solid density profiles as a function of laser heating time

when compared to the other two methods. Similarly, due to comparatively higher temperature distribution, the decomposition of the solid is higher within the material for the Fiber laser case as illustrated in Fig. 15(b).

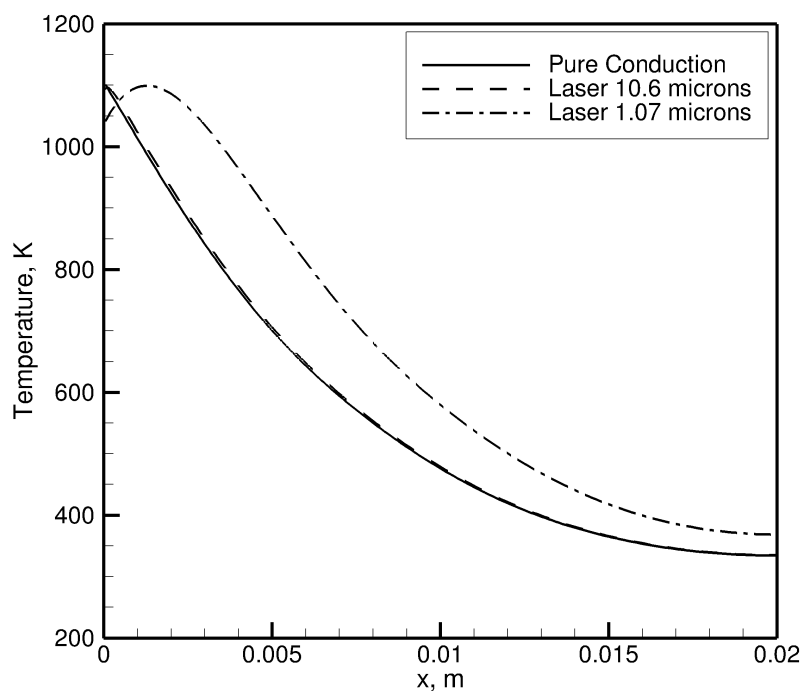

(a) Temperature profiles at various locations within the sample

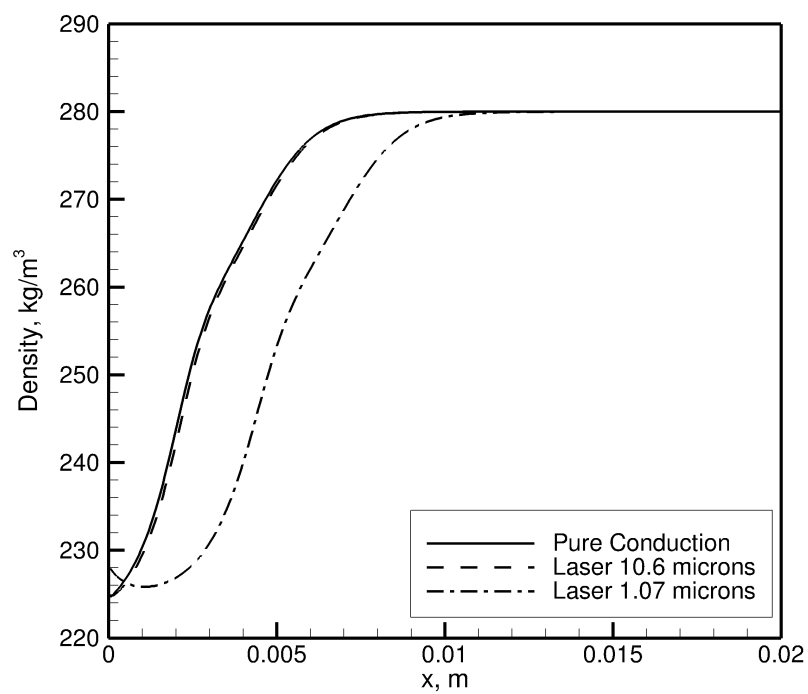

(b) Density profiles at various locations within the sample

Figure 15. Temperature and solid density profiles along the sample at the end of laser heating time

The extent to which the energy is deposited in the sample for two-wavelength lasers is interpreted in Fig. 16. The energy absorbed is to a thin layer from the heating surface for the $\mathrm{CO}_{2}$ laser, whereas the deposition of the energy goes deep for Fiber laser as expected. Thus, the simulation results match the behavior observed from the experimental results.

\section{III.C.1. Role of absorption coefficient}

The extent to which the energy gets absorbed within the material is observed in Fig. 16. It can be inferred that the absorption is in the form of a layer. In order to investigate it more, known laser wavelengths, as given in Table 3, are taken, and the simulations are run. Figure 17 shows the results of the simulations. It can be seen that the layer of energy absorbed within the material is inversely proportional to the absorption coefficient. It is interesting to note that the wavelength of the laser dictates the layer through which energy 


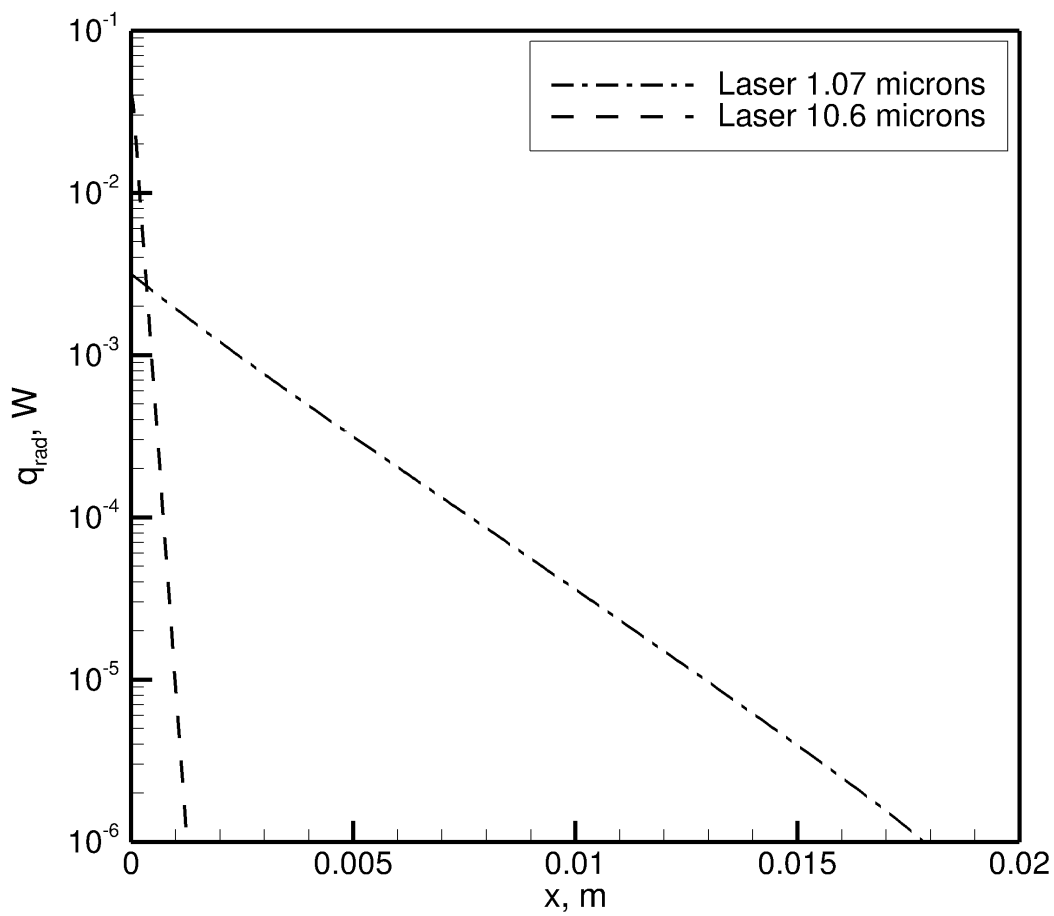

Figure 16. Radiation source term for two laser simulations along the sample at the end of laser heating time

will be absorbed within the material.

In order to understand the role of absorption coefficient in more detail, the current optical properties of LI-900 were multiplied by 100, and the simulations were run for both Fiber laser and $\mathrm{CO}_{2}$ laser. It can be seen from Fig. 18 that the profiles for Fiber and $\mathrm{CO}_{2}$ lasers match each other and follow the pure conduction with a minute difference. With high absorption coefficients, the energy is consumed within a thin layer at the surface. The same behavior can be observed for low absorption coefficients where the energy gets deposited deep inside instead of at the surface.

\section{Conclusion}

A coupling scheme between the material response code KATS-MR and a radiative transfer equation (RTE) solver was constructed to study the effects of radiation transport within ablative materials. A P-1 approximation model is used to compute RTE. Verification of RTE was performed by comparing the numerical results with an analytical solution. Validation of the coupled scheme was performed by comparing the temperature profiles of pure conduction simulation with conduction coupled radiative emission simulation. The cases considered for validation study were those of Marschall et al., a 3D Block, a 2D IsoQ sample, and the Stardust entry capsule. The results show good agreement, with the relative error between the two methods below $10 \%$. Laser ablation simulations were run mimicking the White experiment, and the material response of the material was studied. The simulation results matched well with the behavior concluded from the White experiments.

The results from the validation study indicated that the thermal response could be simulated accurately with the coupling scheme. The validation conducted on multidimensional meshes implies the high robustness of the coupling scheme. The laser ablation simulations numerically confirm the experimental observations of White and conclude that the spectral radiative heat flux could impact the material response for certain types of materials. In light of the results obtained with the efficient coupling scheme presented here, the next step is to study the impact of shock layer radiation on the material response. 


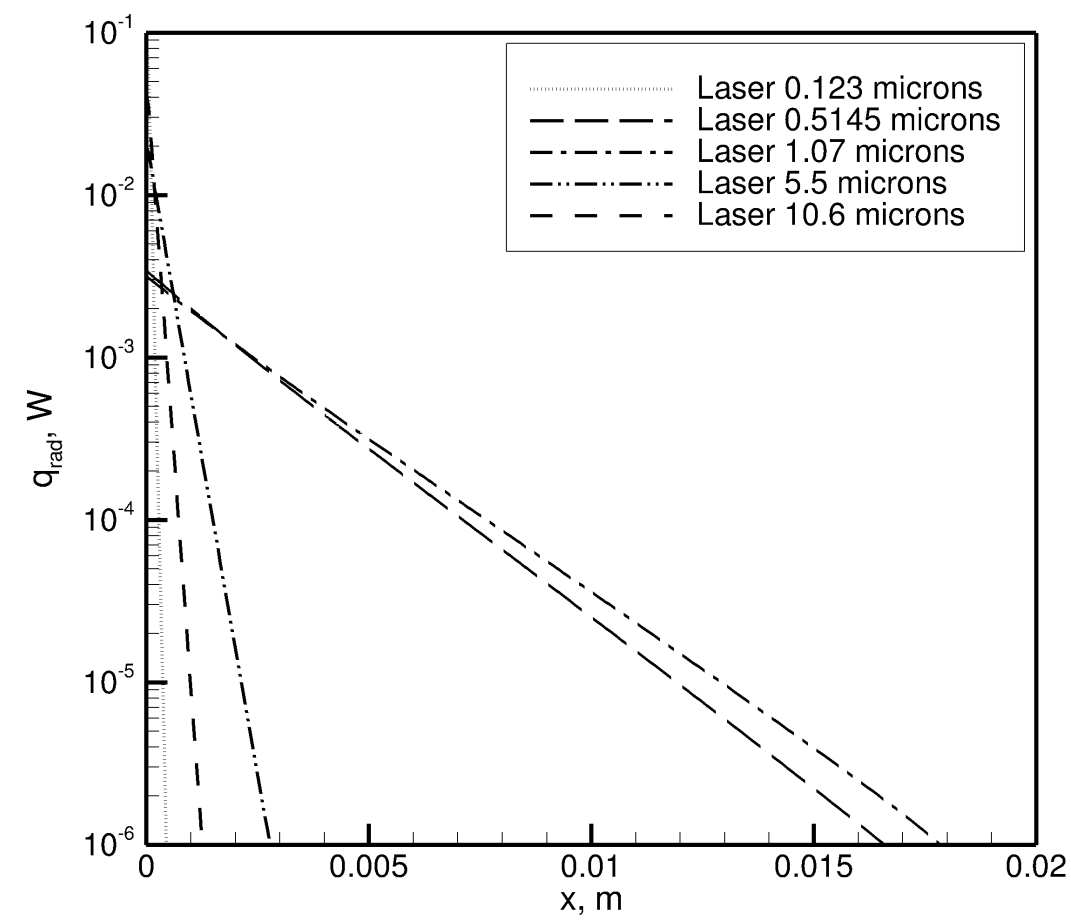

Figure 17. Radiation source term for different types lasers along the sample at the end of laser heating time

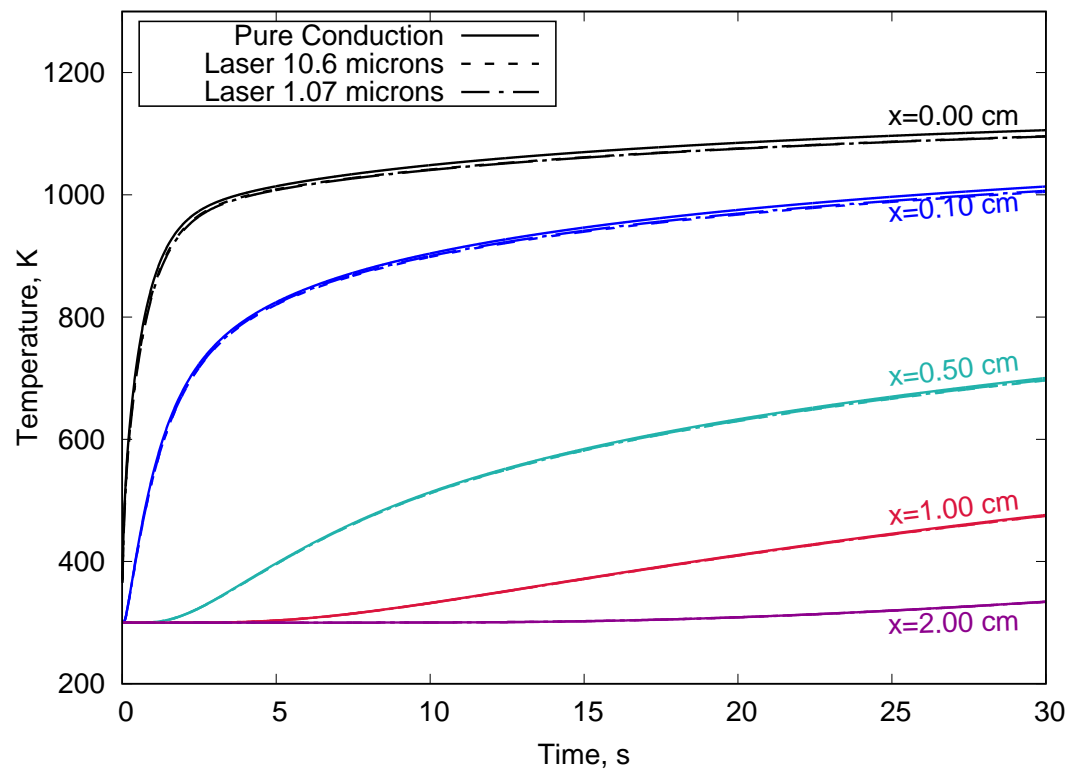

Figure 18. Temperature profiles for simulations with modified optical properties as a function of laser heating time 


\title{
V. Acknowledgements
}

Financial support for this work was provided by the NASA SpaceTech - REDDI - 2018 - ESI grant 80NSSC19K0218.

\section{References}

\author{
${ }^{1}$ Bowman, W. H. and Lawrence, R. M., "Space Resource. Ablative materials for high-temperature thermal protection of \\ space vehicles," Journal of Chemical Education, Vol. 48, No. 10, 10 1971, pp. 690. \\ doi:10.1021/ed048p690 \\ ${ }^{2}$ Lee, S.-C. and George R. Cunnington, J., "Theoretical Models for Radiative Transfer in Fibrous Media," Annual Review \\ of Heat Transfer, Vol. 9, 1998, pp. 159-218. \\ doi:10.1615/AnnualRevHeatTransfer.v9.50 \\ ${ }^{3}$ Duffa, G., Ablative Thermal Protection Systems Modeling, ISBN 978162410171 7, American Institute of Aeronautics \\ and Astronautics, April 2013. \\ ${ }^{4}$ Stackpoole, M., Sepka, S., Cozmuta, I., and Kontinos, D., "Post-Flight Evaluation of Stardust Sample Return Capsule \\ Forebody Heatshield Material," 46th AIAA Aerospace Sciences Meeting and Exhibit, AIAA Paper 2008-1202, American Insti- \\ tute of Aeronautics and Astronautics, Reno, Nevada, January 2008. \\ doi:10.2514/6.2008-1202 \\ ${ }^{5}$ White, S., "Solar Tower Radiation Testing of Phenolic Impregnated Carbon Ablator," Journal of Spacecraft and Rockets, \\ Vol. 49, No. 5, September 2012, pp. 889-893. \\ doi:10.2514/1.A32104 \\ ${ }^{6}$ White, S., "Effects of Laser Wavelength on Ablator Testing," 38th Annual Conference on Composites, Materials and \\ Structures, Cocoa Beach, Florida, January 2014. \\ doi:2060/20140011553 \\ ${ }^{7}$ Bose, D., McCorkle, E., Thompson, C., Bogdanoff, D., Prabhu, D., Allen, G., and Grinstead, J., "Analysis and Model \\ Validation of Shock Layer Radiation in Air," 46th AIAA Aerospace Sciences Meeting and Exhibit, AIAA Paper 2008-1246, \\ Reno, Nevada, January 2008. \\ doi:10.2514/6.2008-1246 \\ ${ }^{8}$ Martin, A. and Panesi, M., "Radiative transmission and absorption within the ablative heat shield of hypersonic vehicles," \\ AIAA Aviation 2020 Forum, AIAA Paper 2020-3276, American Institute of Aeronautics and Astronautics, Virtual Event, June \\ 2020 . \\ doi:10.2514/6.2020-3276 \\ ${ }^{9}$ Weng, H. and Martin, A., "Multidimensional Modeling of Pyrolysis Gas Transport Inside Charring Ablative Materials," \\ Journal of Thermophysics and Heat Transfer, Vol. 28, No. 4, October 2014, pp. 583-597. \\ doi:10.2514/1.T4434 \\ ${ }^{10}$ Davuluri, R. S. C., Zhang, H., and Martin, A., "Numerical Study of Spallation Phenomenon in an Arc-Jet Environment," \\ Journal of Thermophysics and Heat Transfer, Vol. 30, No. 1, January 2016, pp. 32-41. \\ doi:10.2514/1.T4586 \\ ${ }^{11}$ Davuluri, R. S. C., Zhang, H., and Martin, A., "Effects of spalled particles thermal degradation on a hypersonic flow \\ field environment," 54th AIAA Aerospace Sciences Meeting, AIAA Paper 2016-0248, San Diego, California, January 2016. \\ doi:10.2514/6.2016-0248 \\ ${ }^{12} \mathrm{Fu}$, R., Weng, H., Wenk, J. F., and Martin, A., "Thermomechanical Coupling for Charring Ablators," Journal of \\ Thermophysics and Heat Transfer, Vol. 32, No. 2, April 2018, pp. 369-379. \\ doi:10.2514/1.T5194 \\ ${ }^{13} \mathrm{Fu}, \mathrm{R}$., Weng, H., Wenk, J. F., and Martin, A., "Thermal expansion of charring ablative materials," Journal of Thermo- \\ physics and Heat Transfer, Vol. 34, No. 1, January 2020, pp. 57-65. \\ doi: $10.2514 / 1$.T5718 \\ ${ }^{14}$ Ümran Düzel, Schroeder, O. M., Zhang, H., and Martin, A., "Computational Prediction of NASA Langley HYMETS Arc \\ Jet Flow with KATS," 2018 AIAA Aerospace Sciences Meeting, AIAA Paper 2018-1719, American Institute of Aeronautics \\ and Astronautics, Kissimmee, Florida, January 2018. \\ doi:10.2514/6.2018-1719 \\ ${ }^{15}$ Ümran Düzel and Martin, A., "Modeling High Velocity Flow Through Porous Media," AIAA Scitech 2020 Forum, AIAA \\ Paper 2020-0486, Orlando, Florida, January 2020. \\ doi:10.2514/6.2020-0486 \\ ${ }^{16}$ Balay, S., Gropp, W. D., McInnes, L. C., and Smith, B. F., "Efficient Management of Parallelism in Object Oriented \\ Numerical Software Libraries," Modern Software Tools in Scientific Computing, edited by E. Arge, A. M. Bruaset, and H. P. \\ Langtangen, Birkhäuser Press, Boston, MA, 1997. \\ doi:10.1007/978-1-4612-1986-6_8 \\ ${ }^{17}$ Balay, S., Brown, J., Buschelman, K., Eijkhout, V., Gropp, W. D., Kaushik, D., Knepley, M. G., McInnes, L. C., Smith, \\ B. F., and Zhang, H., "PETSc Users Manual," Tech. Rep. ANL-95/11 - Revision 3.3, Argonne National Laboratory, 2012. \\ ${ }^{18}$ Balay, S., Abhyankar, S., Adams, M. F., Brown, J., Brune, P., Buschelman, K., Eijkhout, V., Gropp, W. D., Kaushik, D., \\ Knepley, M. G., McInnes, L. C., Rupp, K., Smith, B. F., and Zhang, H., "PETSc Web page," http://www.mcs.anl.gov/petsc, \\ 2014. \\ ${ }^{19}$ Karypis, G. and Kumar, V., "A Fast and High Quality Multilevel Scheme for Partitioning Irregular Graphs," SIAM
}


Journal on Scientific Computing, Vol. 20, No. 1, January 1998, pp. 359-392. doi:10.1137/S1064827595287997

${ }^{20}$ Walker, D. W. and Dongarra, J. J., "MPI: a standard message passing interface," Supercomputer, Vol. 12, No. 1, December 1996, pp. 56-58.

https://www. scopus. com/record/display.uri?eid=2-s2.0-0002789358\&origin=inward\&txGid=b9b115ae3d17f3587282ac510844aea7

${ }^{21}$ Weng, H. and Martin, A., "Numerical Investigation of Thermal Response Using Orthotropic Charring Ablative Material," Journal of Thermophysics and Heat Transfer, Vol. 29, No. 3, July 2015, pp. 429-438. doi:10.2514/1.T4576

${ }^{22}$ Weng, H., Ümran Düzel, Fu, R., and Martin, A., "Geometric Effects on Charring Ablator: Modeling the Full-Scale Stardust Heat Shield," Journal of Spacecraft and Rockets, Vol. 58, No. 2, March 2021, pp. 302-315. doi:10.2514/1.A34828

${ }^{23}$ Modest, M. F., Radiative Heat Transfer, ISBN 978012503163 9, Academic Press, 2nd ed., March 2003.

${ }^{24}$ Ravishankar, M., Spherical Harmonics based techniques for solution of the Radiative Transfer Equation, Master's thesis, The Ohio State University, Columbus, Ohio, 2009.

http://rave.ohiolink.edu/etdc/view?acc_num=osu1243955769

${ }^{25} \mathrm{Liu}, \mathrm{F}$., Swithenbank, J., and Garbett, E. S., "The boundary condition of the $\mathrm{P}_{N}$-approximation used to solve the radiative transfer equation," International Journal of Heat and Mass Transfer, Vol. 35, No. 8, August 1992, pp. $2043-2052$. doi:10.1016/0017-9310(92)90205-7

${ }^{26}$ Eby, S. D., Trepanier, J. Y., and Zhang, X. D., "Modelling radiative transfer in $\mathrm{SF}_{6}$ circuit-breaker arcs with the P-1 approximation," Journal of Physics D: Applied Physics, Vol. 31, No. 13, July 1998, pp. 1578-1588. doi:10.1088/0022-3727/31/13/012

${ }^{27}$ Banerji, N., The effects of radiation on ablative heat shields during atmospheric entry, Ph.d. thesis, Ecole Polytechnique Federale De Lausanne, Lausanne, Switzerland, June 2017. doi:10.5075/epfl-thesis-7681

${ }^{28}$ Marschall, J., Maddren, J., and Parks, J., "Internal Radiation Transport and Effective Thermal Conductivity of Fibrous Ceramic Insulation," 35th AIAA Thermophysics Conference, AIAA Paper 2001-2822, Anaheim, California, June 2001. doi:10.2514/6.2001-2822

${ }^{29}$ Williams, S. D. and Curry, D. M., "Thermal Protection Materials: Thermophysical Property Data," Reference Publication NASA-RP-1289, NASA, Houston, Texas, December 1992.

${ }^{30}$ Boyd, I. D., Trumble, K. A., and Wright, M. J., "Modeling of Stardust Entry at High Altitude, Part 1: Flowfield Analysis," Journal of Spacecraft and Rockets, Vol. 47, No. 5, September 2010, pp. 708-717. doi:10.2514/1.37360

${ }^{31}$ Lachaud, J., van Eekelen, T., Bianchi, D., and Martin, A., "TACOT v3.0," Ablation Workshop: Code Comparison, 4, 2014.

doi:10.13023/ablation.test.TACOT 